\title{
X-ray Spectroscopy of Heterocyclic Biochemicals: Xanthine, Hypoxanthine, and Caffeine
}

\author{
Oksana Plekan, ${ }^{\dagger, \ddagger}$ Vitaliy Feyer, ${ }^{\dagger, \#}$ Robert Richter, ${ }^{\dagger}$ Angelica Moise, ${ }^{\dagger}$ Marcello Coreno, ${ }^{\S}$
}

Kevin C. Prince, ${ }^{\dagger, \|, *}$ Irina L. Zaytseva, ${ }^{\perp}$ Tatyana E. Moskovskaya, ${ }^{\perp}$ Dmitriy Yu. Soshnikov, ${ }^{\perp}$ and Alexander B. Trofimov ${ }^{\perp, O}$

\author{
${ }^{\dagger}$ Sincrotrone Trieste, Area Science Park, I-34149 Basovizza (Trieste), Italy \\ ${ }^{\S}$ CNR-IMIP, Montelibretti (Rome), I-00016 Italy \\ "Istituto Officina dei Materiali, Consiglio Nazionale delle Ricerche, Area Science Park, I-34149 Trieste, Italy \\ ${ }^{\perp}$ Laboratory of Quantum Chemistry, Irkutsk State University, 664003 Irkutsk, Russia \\ Favorsky Institute of Chemistry, SB RAS, 664033 Irkutsk, Russia
}

\section{Supporting Information}

ABSTRACT: The electronic structures of the purine derivatives xanthine, hypoxanthine and caffeine have been investigated in the gas phase using $\mathrm{C}, \mathrm{N}$, and $\mathrm{O}$ 1s X-ray photoemission (XPS) and near edge X-ray absorption fine structure (NEXAFS) spectroscopy. The results have been interpreted by means of $a b$ initio calculations using the third-order algebraic-diagrammatic construction $(\mathrm{ADC}(3))$ method for the one-particle Green's function and the second-order $\mathrm{ADC}$ method $(\mathrm{ADC}(2))$ for the polarization propagator. The carbon, nitrogen and oxygen K-edge NEXAFS spectra of xanthine and caffeine are very similar, since the molecules differ only by substitution of three hydrogen atoms by methyl groups. For hypoxanthine, the electronic structure

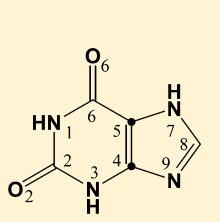

xanthine

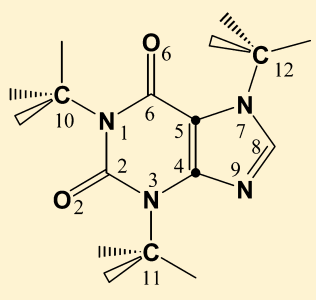

caffeine and spectra differ considerably from xanthine as the purine ring is more highly conjugated, and there is one less oxo group. Effects due to oxo-hydroxy tautomerism were not observed. However, the two oxo tautomeric forms of hypoxanthine oxo- $\mathrm{N}(9)$ $\mathrm{H}$ and oxo-N(7)-H are populated in the gas phase, and the $\mathrm{C}$ 1s spectra can be simulated only by taking account of these two tautomers, with appropriate Boltzmann population ratios which we have also calculated. For xanthine and caffeine, single tautomeric forms were observed.

\section{INTRODUCTION}

Heterocyclic organic compounds like the purine derivatives xanthine (Xan), hypoxanthine (Hyp), and caffeine (Caff), see Figure 1, play an important role in biology, and they are interesting systems from biochemical, pharmacological, and chemical points of view. ${ }^{1,2}$ For instance, hypoxanthine is found as a minor purine base in tRNA, while in the catabolism of purines, it is a substrate of the metalloenzyme xanthine oxidase in the production of uric acid. ${ }^{1}$ Xanthine and hypoxanthine can arise as intermediates of nucleic acid degradation, since they are the products of the deamination of adenine and guanine (respectively), and they could have mutagenic effects. ${ }^{3}$ Xanthine is also one of the purines which could have been present on a primitive, prebiotic Earth, possibly being formed in frozen ammonium cyanide solutions as has been demonstrated by Miyakawa et $\mathrm{al}^{4}$ or being brought to earth by carbonaceous chondrite meteorites. ${ }^{5}$ Many xanthine derivatives are naturally occurring drugs which find use as central nervous system stimulants, and the best known is caffeine, one of the most widely consumed, pharmacologically active substances. ${ }^{6}$

In recent years there has been colossal progress in the study of biological molecules (such as amino acids, DNA/RNA bases and peptides) in the gas phase, ${ }^{7}$ because gas phase spectroscopy lends itself ideally to the study of electronic structure of molecules without the effect of solvents, and provides important data for comparison with theory. Understanding the stability of the tautomeric forms of xanthine derivatives as well as their electronic structure can provide important information about their biological activity and possibly their involvement in early prebiotic scenarios.

There are less experimental spectroscopic investigations of these heterocyclic organic compounds than of their parent compound purine and the canonical purine nucleobases adenine and guanine..$^{7-11}$ In the late 1970 s the valence shell electronic structure of xanthine and related molecules was studied by UPS with He I radiation, ${ }^{12-15}$ so the information was limited to the binding energy range of the outer-valence orbitals. A series of purine bases has been studied experimentally by XPS. ${ }^{16}$ Little is known about the electronic states and excited state dynamics of xanthine derivatives, but more is known about their vibrational properties. ${ }^{17-20}$

Received: January 14, 2012

Revised: $\quad$ May 21, 2012

Published: May 23, 2012 
<smiles>O=c1[nH]cnc2[nH]cnc12</smiles><smiles>O=c1[nH]cnc2nc[nH]c12</smiles>

1<smiles>Oc1ncnc2[nH]cnc12</smiles><smiles>OC1NCNc2[nH]cnc21</smiles><smiles>O=c1nc[nH]c2nc[nH]c12</smiles>

5

A<smiles>O=c1[nH]c(=O)c2[nH]cnc2[nH]1</smiles><smiles></smiles>

Figure 1. (A) Schematic structures of the six most stable tautomeric forms of hypoxanthine (1-6). (B) Schematic structure of xanthine. (C) schematic structure of caffeine.

It is well-known that enzymes attack purines at preferred positions, and therefore, their tautomerism may be important. Tautomers of xanthine and hypoxanthine have been the subject of theoretical calculations, ${ }^{21-25}$ for instance, Xan and Hyp were investigated by Kondratyuk and coauthors ${ }^{22}$ using semiempirical quantum-chemical AM1 methods. In this work the geometric and electronic structures and energetic features of complete molecular-zwitterionic families of tautomers of xanthine and hypoxanthine were determined. $\mathrm{Civcir}^{25}$ has also performed AM1 and PM3 quantum-chemical calculations at the SCF level for xanthine. These calculations show that the two dioxo tautomers, denoted by the authors as $\mathrm{X} 1,3,7$ and $\mathrm{X} 1,3,9$, are the predominant species at room temperature in the gas and aqueous phases. The IR vibrational spectrum of Hyp in the gas phase has been investigated by Costas et al. ${ }^{26}$ and interpreted in terms of the contributions of several tautomers. They found that the two $\mathrm{N}(1)-\mathrm{H}$ oxo tautomers of hypoxanthine are energetically most stable. Hypoxanthine isolated in low-temperature $\mathrm{Ar}$ matrices has been studied using Fourier transform infrared spectroscopy. ${ }^{27}$ The two most stable tautomeric forms of hypoxanthine, oxo-N(9)- $\mathrm{H}$ and oxo$\mathrm{N}(7)-\mathrm{H}$, as well as a very small amount of the minor hydroxy$\mathrm{N}(9)-\mathrm{H}$ tautomer were observed. A theoretical investigation of the electronic spectra, excited-state geometries, and molecular electrostatic potentials of Hyp has been performed by Shukla et $\mathrm{al}^{28}$ It has been shown that hydration has an appreciable effect on the relative tautomer populations and on the structure of the transition states corresponding to the proton transfer from the oxo to the hydroxy tautomeric form of hypoxanthine.
Up to now, there appear to be no experimental results available about the electronic structure of xanthine derivatives studied by soft X-ray photoemission spectroscopy. Core level photoemission spectroscopy can provide chemical state information about the atoms in a molecule as the spectra are sensitive to the local electronic environment of the ionized atoms. Similarly, X-ray absorption spectra are sensitive not only to the ground state electronic structure, but particularly sensitive to the unoccupied states, and thus provide complementary information about the electronic structure. In the present work, we report the experimental XPS and NEXAFS spectra at the three core edges (C, N, O) of xanthine, hypoxanthine, and caffeine in the gas phase and the results are interpreted via theoretical calculations. Our calculations predict the relative binding energies of the core level features observed in the experimental photoemission results, and provide a full assignment.

Other techniques have also been applied to study the properties of xanthine derivatives. ${ }^{29-31}$ The resonant twophoton ionization (R2PI), UV-UV, and IR-UV double resonance spectra of xanthine seeded in a supersonic jet by laser desorption have been measured by Callahan et al. ${ }^{32}$ Recently results of an investigation of electronically excited states of Caff and its 1:1 complex with water, by resonant twophoton ionization (R2PI) and UV-UV hole-burning techniques, have been reported by Kim et al. ${ }^{33}$ In this work, the strong vibronic coupling between a pair of close-lying $\pi-\pi^{*}$ and $n-\pi^{*}$ transitions was proposed to be responsible for the broad spectral feature that was observed. Infrared and Raman spectra of Caff in the gas phase and in aqueous solution have been simulated using hybrid density functional theory. ${ }^{34,35}$ The molecular structure of caffeine has been determined by means of gas phase electron diffraction and supported by results of MP2 and B3LYP calculations with the 6-31G** basis set. ${ }^{36}$ Recently the calculated valence photoelectron spectrum of caffeine has been reported ${ }^{37}$ and compared with the experimental results. ${ }^{38}$

\section{EXPERIMENTAL AND THEORETICAL METHODS}

2.1. Experimental Section. The samples were obtained from Sigma-Aldrich in the form of crystalline powder with minimum purity of $99 \%$ and used without any further purification. They were evaporated from a noncommercial furnace with an effusive nozzle and were checked before the experiment using photoionization mass spectroscopy, to ensure that there are no effects due to thermal decomposition of the product. The spectra were recorded at sample temperatures of 215,165 , and $75{ }^{\circ} \mathrm{C}$ for xanthine, hypoxanthine and caffeine, respectively. During the experiment the sample quality was monitored by valence band photoemission. The peak energies of the valence spectra were similar to previously published He I spectra $^{13}$ and no effects of thermal decomposition were observed. The photoionization mass spectra and valence band photoemission spectra of xanthine and its derivatives have been published elsewhere. $^{38}$

The measurements were performed at the Gas phase photoemission beamline at the ELETTRA synchrotron light source in Trieste (Italy). ${ }^{39}$ Briefly, this beamline comprises an undulator source with a $12.5 \mathrm{~cm}$ period, a variable-angle spherical grating monochromator and two refocusing mirrors, and it provides high-intensity collimated radiation in the photon energy range $15-1000 \mathrm{eV}$. The photoemission spectra were taken using a $150 \mathrm{~mm}$ hemispherical electron energy 
Table 1. Relative Energies $\Delta E(\mathrm{~kJ} / \mathrm{mol})$ of Hypoxanthine Tautomers (Figure 1) Computed Using MP2 and CCSD Methods with cc-pVTZ Basis Sets, Relative Gibbs Free Energies $\Delta G(\mathrm{~kJ} / \mathrm{mol})$, and Boltzmann Population Ratios (BPR) for the Given Temperatures

\begin{tabular}{|c|c|c|c|c|c|c|c|}
\hline \multirow[b]{2}{*}{ tautomer } & \multicolumn{2}{|c|}{$\Delta E$} & \multicolumn{2}{|c|}{$\Delta G^{c}$} & \multicolumn{2}{|c|}{$\mathrm{BPR}^{c}$} & \multirow{2}{*}{$\frac{\mathrm{BPR}^{d}}{298.15 \mathrm{~K}}$} \\
\hline & $\mathrm{MP}^{a}{ }^{a}$ & $\operatorname{CCSD}^{b}$ & $298 \mathrm{~K}$ & $438 \mathrm{~K}$ & $298 \mathrm{~K}$ & $438 \mathrm{~K}$ & \\
\hline 1 & 2.80 & 2.43 & 2.38 & 2.38 & 0.275 & 0.330 & 0.349 \\
\hline 2 & 0.0 & 0.0 & 0.0 & 0.0 & 0.717 & 0.638 & 0.620 \\
\hline 3 & 11.00 & 11.80 & 11.88 & 12.09 & 0.006 & 0.023 & 0.030 \\
\hline 4 & 14.69 & 15.90 & 16.07 & 16.28 & 0.001 & 0.007 & \\
\hline 5 & 33.56 & 32.51 & 31.21 & 30.75 & 0.0 & 0.0 & \\
\hline 6 & 22.18 & 23.77 & 22.84 & 22.84 & 0.0 & 0.001 & 0.002 \\
\hline
\end{tabular}

${ }^{a} \Delta E$ and geometry optimization at the MP2/cc-pVTZ level of theory. ${ }^{b} \mathrm{CCSD} / \mathrm{cc}-\mathrm{pVTZ} / / \mathrm{MP} 2 / \mathrm{cc}-\mathrm{pVTZ}$ calculations. ${ }^{c} \Delta G$ are calculated using $\Delta E(\mathrm{CCSD} / \mathrm{cc}-\mathrm{pVTZ} / / \mathrm{MP} 2 / \mathrm{cc}-\mathrm{pVTZ})$ and thermochemical corrections for the given $\mathrm{T}$ calculated at the B3LYP/6-311G** level of theory.

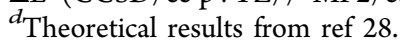
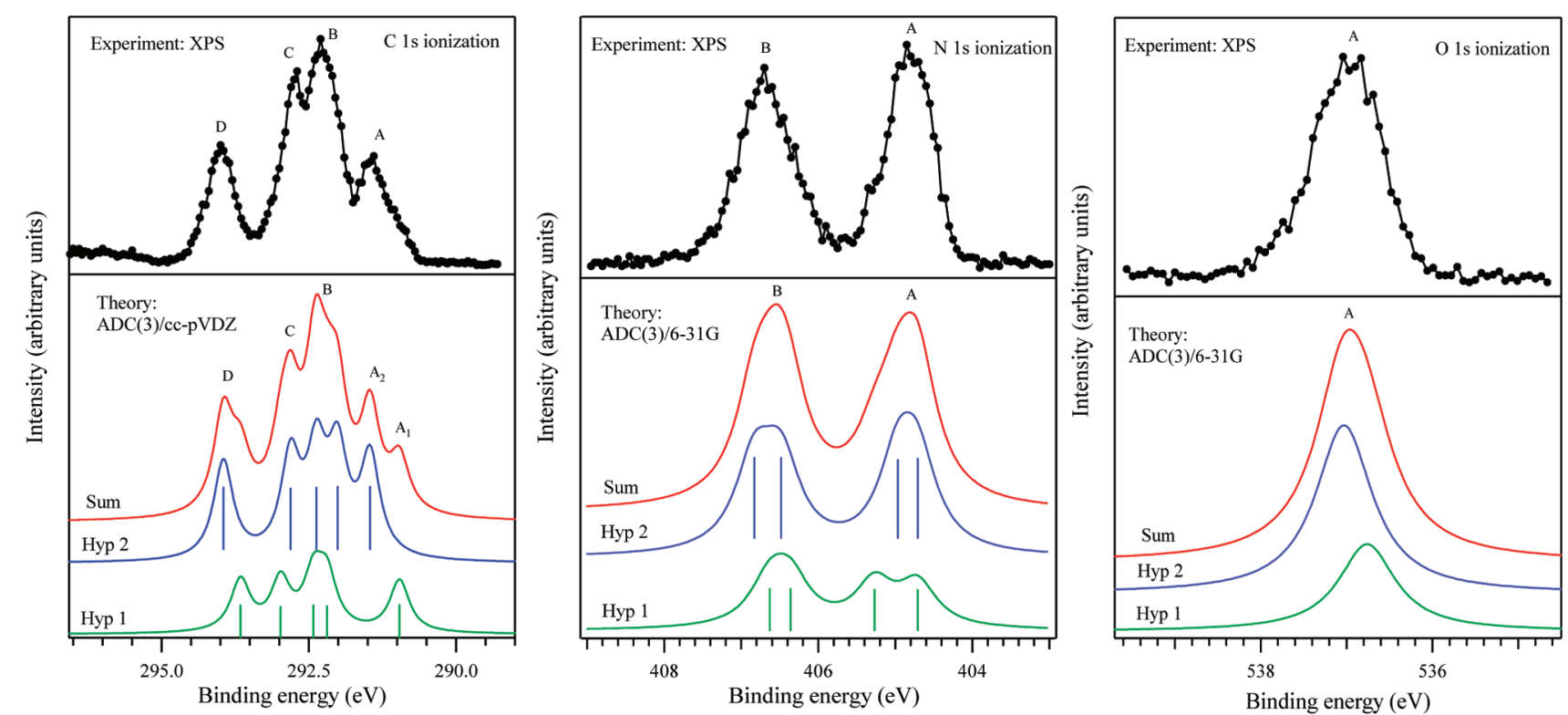

Figure 2. Experimental and theoretical carbon 1s, nitrogen $1 \mathrm{~s}$ and oxygen $1 \mathrm{~s}$ photoionization spectra of hypoxanthine. Tautomer $1=$ green line and tautomer 2 = blue line, BPR-weighted sum = red line. The following parameters were used to generate the theoretical curves (see text for details): shift $=-5.1 \mathrm{eV}$ and fwhm $=0.4 \mathrm{eV}$ (C 1s transitions), shift $=-7.8 \mathrm{eV}$ and fwhm $=0.6 \mathrm{eV}(\mathrm{N}$ 1s transitions $)$, and shift $=-10.0 \mathrm{eV}$ and fwhm $=0.8 \mathrm{eV}$ (O 1 s transitions).

analyzer, equipped with 6 channel electron multipliers. The near edge X-ray absorption fine structure spectra were recorded by collecting the total ion yield signal using a channel electron multiplier placed close to the ionization region. The spectra at the carbon, nitrogen and oxygen K-edges were normalized to the photon flux measured by a photodiode. The experimental methods, the resolution of the measured spectra as well as the calibration procedure have been described in detail elsewhere. $^{40,41}$

2.2. Theoretical Approach. A theoretical approach essentially similar to that of our previous study of nucleobases (adenine, cytosine, guanine) ${ }^{40,42-44}$ was employed, and we summarize here only the main details. The energies $\Omega$ and the optical oscillator strengths $f$ of the vertical K-shell excitations were evaluated using the second-order algebraic-diagrammatic construction $(\mathrm{ADC}(2))$ approximation scheme for the polarization propagator ${ }^{45,46}$ adapted for the case of K-shell ionization by means of an additional core-valence separation (CVS) approximation. ${ }^{47-49}$ The polarization propagator $\mathrm{ADC}(2) /$ CVS calculations were performed using the $6-31+\mathrm{G}$ basis set augmented by diffuse functions at second-row atoms. ${ }^{50,51}$ The energies $(\Omega)$ and the relative intensities $(P)$ of the vertical ionization transitions were computed using the third-order algebraic-diagrammatic construction $(\mathrm{ADC}(3))$ approximation scheme for the one-particle Green's function ${ }^{52-55}$ and 6-31G basis set. ${ }^{50,51}$ For the vertical $\mathrm{C} 1 \mathrm{~s}$ ionization transitions of hypoxanthine tautomers, in addition to the third-order $\mathrm{ADC}(3)$ scheme the "strict" and "extended" fourth-order ADC/CVS schemes $(\mathrm{ADC}(4) \mathrm{s} \text { and } \mathrm{ADC}(4) \text {, respectively) })^{52,55}$ were employed to test the effect of improved electron correlation and orbital relaxation treatments on the ionization spectrum. Here, also the basis set effect was studied by performing calculations with the more flexible $6-31+G^{50,51}$ and cc$\mathrm{pVDZ}^{56-58}$ basis sets. The calculations were performed using the polarization propagator and one-particle Green's function ADC codes ${ }^{59}$ interfaced to the GAMESS (Us) program. ${ }^{60}$

The ground-state geometrical parameters of the molecules were obtained by means of the full geometry optimization procedure using the second-order Møller-Plesset perturbation theory (MP2) and cc-pVTZ basis set. ${ }^{56-58}$ The ground-state MP2 calculations were carried out using the GAUSSIAN package of programs. ${ }^{61}$ 
The theoretical spectral envelopes were generated by convoluting the results for the discrete transitions with Lorentzian functions. The full width at half-maximum (fwhm) of the theoretical curves was chosen to match the width of the peaks in the experimental spectra. This accounts for the spectrometer resolution, the unresolved vibrational structure and the natural lifetimes of the core-hole states. Also, for the sake of comparison with experimental spectra an overall shift of the theoretical spectra was applied, which eliminates various systematic errors of the present calculations.

\section{RESULTS AND DISCUSSION}

3.1. Thermochemistry of the Most Stable Tautomers of Hypoxanthine. Separate quantum chemical calculations were carried out in order to determine the structure and relative stability of hypoxanthine tautomers 1-6 (Figure 1A). The ground-state molecular geometries of the tautomers were optimized at the MP2/cc-pVTZ level of theory. The total ground-state electronic energies of the optimal structures were then finalized using the coupled clusters singles and doubles approach (CCSD). This type of theoretical treatment is abbreviated below as CCSD/cc-pVTZ//MP2/cc-pVTZ. The resulting energies were combined with the thermochemical corrections computed using the density functional theory (DFT) approach with the Becke-three-parameters-Lee-YangParr (B3LYP) functional ${ }^{62,63}$ and the $6-311 G^{* *}$ basis set $^{64}$ to yield the Gibbs free energies and Boltzmann population ratios (BPRs) for the required temperatures. The calculations were performed with the GAUSSIAN package of programs. ${ }^{61}$ The results are summarized in Table 1. Both the MP2 and CCSD methods predict that the two most stable tautomeric forms of hypoxanthine are oxo-N(7)-H (tautomer 2) and oxo- $\mathrm{N}(9)-\mathrm{H}$ (tautomer 1) with BPRs at $438 \mathrm{~K}$ of 0.64 and 0.33 , respectively. The gas phase population of the hydroxy-N(9)-H tautomer (3) is predicted to be very small, $\mathrm{BPR} \sim 0.023$. These calculated BPRs are in agreement with the published results for the oxo forms. ${ }^{28}$ The tautomers $4-6$ are characterized by higher relative energies and populated negligibly at both standard and experimental temperatures.

3.2. Core Level Photoemission. 3.2.1. Hypoxanthine. Our thermochemical calculations predict that the two oxo tautomeric forms of hypoxanthine $\mathrm{N}(7)-\mathrm{H}$ (tautomer 2) and $\mathrm{N}(9)-\mathrm{H}$ (tautomer 1) will be the most populated in our experiment. Their calculated BPRs (Table 1) imply an intensity ratio of roughly $2: 1$, and this has to be accounted for in the assignment of the spectra. The calculated $C$ 1s spectra of the two tautomers are significantly different (Figure 2), first in the position of the lowest transition due to the ionization of the $\mathrm{C}_{5}$ atom which is shifted to lower energy in tautomer 1 with respect to tautomer 2 . This results from the different chemical forms (amino-imino) of the neighboring $\mathrm{N}_{7}$ atoms in the tautomers, which influences the electron density and the corehole screening at the $\mathrm{C}_{5}$ site. Also, sites $\mathrm{C}_{4}, \mathrm{C}_{8}$, and $\mathrm{C}_{2}$ are affected by $\mathrm{N}(7)-\mathrm{H} / \mathrm{N}(9)-\mathrm{H}$ tautomerism so that the relative positions of the corresponding lines in the spectra are not the same in tautomers 1 and 2 .

To verify these results, we have performed calculations using different ADC approximation schemes and basis sets (Table 2). As can be seen, the absolute ionization energies vary considerably from one theoretical level to another. The best agreement with experiment is provided by the $\mathrm{ADC}(4)$ scheme which gives the best treatment of orbital relaxation effects. The $\mathrm{ADC}(4)$ and $\mathrm{ADC}(3)$ ionization energies are uniformly shifted
Table 2. Relative Energies $(\mathrm{eV})^{a}$ of the Vertical C 1s Ionization Transitions of Hypoxanthine Tautomers Calculated Using Different ADC Schemes and Basis Sets

\begin{tabular}{cccccc} 
& & \multicolumn{3}{c}{$6-31 G$} & \\
\cline { 3 - 4 } tautomer & transition & $\mathrm{ADC}(3)$ & $\mathrm{ADC}(4) \mathrm{s}$ & $\mathrm{ADC}(4)$ & $\mathrm{ADC}(3)$ \\
1 & $\left(\mathrm{C}_{5} 1 \mathrm{~s}\right)^{-1}$ & 0.0 & 0.0 & 0.0 & 0.0 \\
2 & $\left(\mathrm{C}_{5} 1 \mathrm{~s}\right)^{-1}$ & 0.58 & 0.62 & 0.62 & 0.50 \\
2 & $\left(\mathrm{C}_{4} 1 \mathrm{~s}\right)^{-1}$ & 0.94 & 0.86 & 0.88 & 1.05 \\
1 & $\left(\mathrm{C}_{8} 1 \mathrm{~s}\right)^{-1}$ & 1.14 & 1.36 & 1.34 & 1.23 \\
2 & $\left(\mathrm{C}_{8} 1 \mathrm{~s}\right)^{-1}$ & 1.30 & 1.45 & 1.44 & 1.41 \\
1 & $\left(\mathrm{C}_{4} 1 \mathrm{~s}\right)^{-1}$ & 1.37 & 1.34 & 1.38 & 1.46 \\
2 & $\left(\mathrm{C}_{2} 1 \mathrm{~s}\right)^{-1}$ & 1.74 & 1.88 & 1.88 & 1.85 \\
1 & $\left(\mathrm{C}_{2} 1 \mathrm{~s}\right)^{-1}$ & 1.93 & 2.06 & 2.00 & 2.02 \\
1 & $\left(\mathrm{C}_{6} 1 \mathrm{~s}\right)^{-1}$ & 2.76 & 2.89 & 2.98 & 2.70 \\
2 & $\left(\mathrm{C}_{6} 1 \mathrm{~s}\right)^{-1}$ & 3.09 & 3.22 & 3.29 & 2.99
\end{tabular}

${ }^{a}$ The ionization energies chosen as the origin, $\left(\mathrm{C}_{5} 1 \mathrm{~s}\right)^{-1}$, are 296.53, 296.0, 292.58, and $296.06 \mathrm{eV}$ at the $\mathrm{ADC}(3) / 6-31 \mathrm{G}, \mathrm{ADC}(4) \mathrm{s} / 6-31 \mathrm{G}$, $\mathrm{ADC}(4) / 6-31 \mathrm{G}$ and $\mathrm{ADC}(3) / \mathrm{cc}-\mathrm{pVDZ}$ level of theory, respectively.

by about $3.5-4 \mathrm{eV}$ to higher energy since these schemes account for relaxation effects to a lesser extent. The basis set effect can be estimated from comparison of the $\mathrm{ADC}(3)$ ionization energies for the 6-31G and cc-pVDZ basis sets, and it is seen to be rather small. The larger basis cc-pVDZ improves the agreement with experiment only slightly. The most important observation here is that the relative positions of the ionization lines in the spectrum are very consistently described at all levels of the ADC theory. This confirms that our theoretical models are sufficiently reliable for assignment of the observed spectra. Also, one may conclude that the least computationally expensive $\mathrm{ADC}(3)$ scheme is sufficient for this purpose, and we use it further in the present work instead of the $\mathrm{ADC}(4)$ scheme used in our previous studies. ${ }^{40,42,43}$

In order to get a better insight into the relative importance of orbital relaxation and electron correlation effects we have performed additional so-called $\triangle$ SCF ("delta” self-consistent field) calculations of the core ionization energies using the 6$31 \mathrm{G}$ basis set and a more extended cc-pVTZ basis set including polarization functions. In the $\triangle$ SCF approach, separate Hartree-Fock (HF) calculations are performed for the neutral ground state and cationic core-hole state. The ionization energy is then obtained as the difference of the respective total energies. The $\triangle$ SCF calculations allow one to take into account orbital relaxation, while they do not treat electron correlation in the ground and cationic states. ${ }^{65,66}$ The relaxation energy can be estimated as the difference of the appropriate HF orbital energies (Koopmans' theorem) and the $\Delta \mathrm{SCF}$ ionization energy. The suitability of the $\triangle \mathrm{SCF}$ approach for computations of core-hole states (which, strictly speaking, cannot be treated by the usual HF theory, since they are excited states) is justified by the same considerations as those leading to the wellestablished core-valence separation approximation, ${ }^{47}$ which was already mentioned above in connection with our ADC calculations.

In Table 3 , the results of our $\triangle$ SCF calculations for hypoxanthine are compared with the $\mathrm{HF}$ and the $\mathrm{ADC}(3)$ data. First of all, we note that the calculated relaxation energy lies within its usual limits. The relaxation corrections obtained for $\mathrm{C}, \mathrm{N}$, and $\mathrm{O}$ atoms using the 6-31G basis are about 12.7-13.7, 16.7-17.0, and $20.3 \mathrm{eV}$, respectively. In the case of the ccpVTZ basis set they are systematically $(1.7-2.0 \mathrm{eV})$ larger and amount to $14.4-15.4,18.6-18.9$, and $22.3 \mathrm{eV}$, respectively. 
Table 3. Vertical C 1s, N 1s, and O 1s Ionization Energies (eV) of Hypoxanthine Tautomers Calculated at the Hartree-Fock (Koopmans' Theorem), $\triangle$ SCF, and ADC(3) Levels of Theory Using 6-31G and cc-pVTZ Basis Sets ${ }^{a}$

\begin{tabular}{|c|c|c|c|c|c|c|}
\hline \multirow[b]{2}{*}{ tautomer } & \multirow[b]{2}{*}{ transition } & \multicolumn{2}{|c|}{ Koopmans' } & \multicolumn{2}{|c|}{$\Delta \mathrm{SCF}$} & \multirow{2}{*}{$\frac{\mathrm{ADC}(3)}{6-31 G}$} \\
\hline & & $6-31 G$ & $\begin{array}{c}\text { cc- } \\
\text { pVTZ }\end{array}$ & $6-31 \mathrm{G}$ & $\begin{array}{c}c c- \\
\text { pVTZ }\end{array}$ & \\
\hline & & 306.97 & 306.38 & 293.36 & 291.14 & 296.53 \\
\hline 1 & $\left(C_{5} 1 \mathrm{~s}\right)^{-1}$ & 0.0 & 0.0 & 0.0 & 0.0 & 0.0 \\
\hline 2 & $\left(C_{5} 1 s\right)^{-1}$ & 0.52 & 0.39 & 0.45 & 0.33 & 0.58 \\
\hline 2 & $\left(C_{4} 1 s\right)^{-1}$ & 1.29 & 1.40 & 1.38 & 1.47 & 0.94 \\
\hline 1 & $\left(C_{8} 1 \mathrm{~s}\right)^{-1}$ & 1.39 & 1.59 & 1.35 & 1.48 & 1.14 \\
\hline 2 & $\left(\begin{array}{lll}C_{8} & 1 s\end{array}\right)^{-1}$ & 1.78 & 1.97 & 1.84 & 1.95 & 1.30 \\
\hline 1 & $\left(\mathrm{C}_{4} 1 \mathrm{~s}\right)^{-1}$ & 1.79 & 1.82 & 1.73 & 1.77 & 1.37 \\
\hline 2 & $\left(C_{2} 1 s\right)^{-1}$ & 2.34 & 2.48 & 2.41 & 2.54 & 1.74 \\
\hline 1 & $\left(C_{2} 1 s\right)^{-1}$ & 2.66 & 2.74 & 2.58 & 2.66 & 1.93 \\
\hline 1 & $\left(C_{6} 1 s\right)^{-1}$ & 3.10 & 2.92 & 3.97 & 3.75 & 2.76 \\
\hline \multirow[t]{2}{*}{2} & $\left(\mathrm{C}_{6} 1 \mathrm{~s}\right)^{-1}$ & 3.41 & 3.19 & 4.20 & 3.94 & 3.09 \\
\hline & & 424.16 & 423.55 & 407.23 & 404.72 & 412.51 \\
\hline 2 & $\left(\mathrm{~N}_{9} 1 \mathrm{~s}\right)^{-1}$ & 0.0 & 0.0 & 0.0 & 0.0 & 0.0 \\
\hline 1 & $\left(\mathrm{~N}_{7} 1 \mathrm{~s}\right)^{-1}$ & 0.04 & 0.04 & 0.03 & -0.01 & 0.01 \\
\hline 2 & $\left(\mathrm{~N}_{3} 1 \mathrm{~s}\right)^{-1}$ & 0.27 & 0.25 & 0.18 & 0.20 & 0.26 \\
\hline 1 & $\left(N_{3} 1 s\right)^{-1}$ & 0.58 & 0.55 & 0.48 & 0.50 & 0.56 \\
\hline 1 & $\left(\mathrm{~N}_{1} 1 \mathrm{~s}\right)^{-1}$ & 1.70 & 1.92 & 1.82 & 2.10 & 1.65 \\
\hline 2 & $\left(N_{1} 1 s\right)^{-1}$ & 1.77 & 1.99 & 1.92 & 2.19 & 1.77 \\
\hline 1 & $\left(\mathrm{~N}_{9} 1 \mathrm{~s}\right)^{-1}$ & 1.78 & 2.02 & 1.97 & 2.25 & 1.92 \\
\hline \multirow[t]{2}{*}{2} & $\left(\mathrm{~N}_{7} 1 \mathrm{~s}\right)^{-1}$ & 1.90 & 2.06 & 2.05 & 2.23 & 2.12 \\
\hline & & 559.06 & 558.46 & 538.76 & 536.21 & 546.76 \\
\hline 1 & $\left(\mathrm{O}_{6} 1 \mathrm{~s}\right)^{-1}$ & 0.0 & 0.0 & 0.0 & 0.0 & 0.0 \\
\hline 2 & $\left(\mathrm{O}_{6} 1 \mathrm{~s}\right)^{-1}$ & 0.23 & 0.22 & 0.22 & 0.21 & 0.27 \\
\hline
\end{tabular}

${ }^{a}$ Relative ionization energies with respect to the $\left(\mathrm{C}_{5} 1 \mathrm{~s}\right)^{-1},\left(\mathrm{~N}_{9} 1 \mathrm{~s}\right)^{-1}$, and $\left(\mathrm{O}_{6} 1 \mathrm{~s}\right)^{-1}$ states of tautomers 1,2 , and 1 , respectively, are given (the absolute ionization energies for these states are shown in the lines preceding transitions of each type).

These results are in agreement with the well-known empirical estimates for $\mathrm{C}, \mathrm{N}$, and $\mathrm{O}$ atoms, which depending on the molecular environment, are of the order 14-15, 17-18, and $20-21 \mathrm{eV}$, respectively. ${ }^{67}$ The relaxation effects are thus seen to be strongly basis set dependent. Accordingly, the absolute vertical ionization energies at the $\Delta$ SCF level decrease by about $2.1-2.6 \mathrm{eV}$ as the basis set is extended from 6-31G to cc-pVTZ and approach the absolute experimental values. By contrast, the Koopmans' ionization energies change only relatively little (0.4-0.8 eV) with extension of the basis.

Although the absolute $\Delta \mathrm{SCF}$ ionization energies, especially for the cc-pVTZ basis set, lie in the correct energy range, their agreement with the benchmark $\mathrm{ADC}(4)$ data is still unsatisfactory, as can be seen from the comparison of the respective 6-31G basis set results for $\mathrm{C} 1 \mathrm{~s}$ spectrum in Tables 2 and 3. The relative positions of the ionization lines in the two methods differ qualitatively, especially for the higher lying transitions. The energies of the latter transitions are overestimated by $\triangle \mathrm{SCF}$ more strongly than are the lower ones. As a result, the $C 1$ s spectrum at the $\Delta$ SCF level appears to be much too extended and is about $1 \mathrm{eV}$ wider than at the $\mathrm{ADC}(4)$ level. Disagreement of the same type can be seen when the $\Delta S C F$ results are compared to the $C 1$ s experimental data (Table 3 ), which confirms that $\Delta$ SCF in general is not reliable enough for interpretation of the observed spectra, even though it performs more satisfactorily in the cases of the $\mathrm{N} 1 \mathrm{~s}$ and $\mathrm{O} 1 \mathrm{~s}$ spectra.
The obvious deficiency of $\triangle S C F$ is the absence of electron correlation treatment in the ground and cationic states, which is crucial for predictions of more subtle spectral details, such as relative positions of the ionization lines. Both effects are treated simultaneously in ADC at the same level of theory, and the actual net corrections due to electron correlation for various transitions can be estimated as the difference of the respective $\mathrm{ADC}(4)$ and $\triangle \mathrm{SCF}$ ionization energies for the 6-31G basis set in Tables 2 and 3. As can be seen, the electron correlation component of the ionization energy is extremely variable and fluctuates between 0.6 and $1.8 \mathrm{eV}$ for different $\mathrm{C}$ atoms. These values are rather small compared to the huge relaxation shifts, but influence significantly the actual shape of the calculated core ionization profile. In particular, the width of the $C 1 \mathrm{~s}$ spectrum becomes correct and compares favorably with the experimental data when the electron correlation is taken into account already at the $\mathrm{ADC}(3)$ level of theory. This effect can be understood as a result of better core hole screening by the correlated electron density, eliminating defects of the less flexible HF description.

As already mentioned above, the relative $\mathrm{ADC}(3)$ ionization energies are in good agreement with the bench-mark $\mathrm{ADC}(4)$ values, which means that the third-order treatment of the ground- and cationic-state electron correlation effects accounts for them already rather well. The difference in the absolute ionization energies is mainly due to insufficient treatment of the orbital relaxation effects.

The C 1s ionization spectral envelopes of tautomers 1 and 2 generated at the $\operatorname{ADC}(3) / c c-p V D Z$ level of theory (Figure 2) are significantly different. Each of these envelopes taken alone does not reproduce the experimental profile, and only their sum with weights proportional to the calculated BPRs yields the envelope that agrees qualitatively well with the experimental spectrum. In particular, the strongly asymmetric peak A and the overall intensity ratios cannot be reproduced by a single tautomer, but are simulated much better by two species. This confirms the existence of two tautomeric forms of hypoxanthine.

The $\mathrm{C}$ 1s experimental spectrum shows 4 features labeled A to $\mathrm{D}$, whereas the theoretical spectrum predicts 5 features, labeled $A_{1}, A_{2}, B, C$, and $D$. It appears that the theory overestimates the splitting between $A_{1}$ and $A_{2}$, so that experimentally they are merged into a single feature; the assignments are given in Table 4. Peak $A$ is due to $C_{5}$, the only carbon atom bonded to two other carbon atoms; peak B to $\mathrm{C}_{4}$ and $\mathrm{C}_{8}$, each of which has two nitrogen neighbors, and a hydrogen or carbon neighbor; peak $\mathrm{C}$ to $\mathrm{C}_{2}$, with two nitrogen neighbors; and peak $\mathrm{D}$ to $\mathrm{C}_{6}$, which is bonded to oxygen and nitrogen. The order of binding energies is consistent with that expected from simple considerations of the electronegativity of nearest neighbors.

The nitrogen spectra show two peaks, due to the imine (A) and amine (B) nitrogen atoms. As there are two of each species in each tautomer, the stoichiometric ratio of the peak intensities is 1 , very close to the experimental ratio of 1.01 . The calculations show that the difference in energy between the various $\mathrm{N} 1 \mathrm{~s}$ levels contributes to the broadening of the peaks, but is not sufficient to split them. As can be seen from the theoretical spectra in Figure 2, the latter strictly applies to the sum and tautomer 2 spectra, but is only partially valid for the spectrum of tautomer 1 where calculations predict splitting of the low energy band into two components. 
Table 4. Energies $\Omega(\mathrm{eV})$, Pole Strengths $P$, Relative Photoelectron Intensities Accounting for BPRs $I_{T}$ of the Vertical C 1s, $\mathbf{N}$ $1 \mathrm{~s}$, and $\mathrm{O} 1 \mathrm{~s}$ Ionization Transitions of Hypoxanthine Tautomers Calculated at the ADC(3)/cc-pVDZ Level of Theory (C 1s) and at the $\operatorname{ADC}(3) / 6-31 G$ Level of Theory ( $N$ 1s, O 1s) in Comparison with the Experimental Data ${ }^{a}$

\begin{tabular}{|c|c|c|c|c|c|c|c|c|}
\hline \multicolumn{4}{|c|}{ Theory } & \multicolumn{5}{|c|}{ Experiment } \\
\hline $\begin{array}{l}\text { Core } \\
\text { level }\end{array}$ & Tautomer & Transition & $\Omega^{\mathrm{a}}$ & $\mathrm{P}$ & $\mathrm{I}_{\mathrm{T}}$ & Maximum & $\mathrm{I}_{\mathrm{Ex}}$ & $\Omega$ \\
\hline \multirow{10}{*}{$\mathrm{C} 1 \mathrm{~s}$} & 1 & $\left(C_{5} 1 \mathrm{~s}\right)^{-1}$ & 290.96 & 0.80 & 0.27 & & & \\
\hline & 2 & $\left(\mathrm{C}_{5} 1 \mathrm{~s}\right)^{-1}$ & 291.46 & 0.79 & 0.52 & A & 0.92 & 291.40 \\
\hline & 2 & $\left(\mathrm{C}_{4} 1 \mathrm{~s}\right)^{-1}$ & 292.01 & 0.79 & 0.52 & \multirow{4}{*}{ B } & \multirow{4}{*}{2.0} & \multirow{4}{*}{292.25} \\
\hline & 1 & $\left(\mathrm{C}_{8} 1 \mathrm{~s}\right)^{-1}$ & 292.19 & 0.77 & 0.26 & & & \\
\hline & 2 & $\left(\mathrm{C}_{8} 1 \mathrm{~s}\right)^{-1}$ & 292.37 & 0.78 & 0.52 & & & \\
\hline & 1 & $\left(\mathrm{C}_{4} 1 \mathrm{~s}\right)^{-1}$ & 292.42 & 0.79 & 0.27 & & & \\
\hline & 2 & $\left(C_{2} 1 s\right)^{-1}$ & 292.81 & 0.77 & 0.51 & \multirow[b]{2}{*}{$\mathrm{C}$} & \multirow[b]{2}{*}{1.0} & \multirow[b]{2}{*}{292.82} \\
\hline & 1 & $\left(\mathrm{C}_{2} 1 \mathrm{~s}\right)^{-1}$ & 292.98 & 0.76 & 0.26 & & & \\
\hline & 1 & $\left(\mathrm{C}_{6} 1 \mathrm{~s}\right)^{-1}$ & 293.66 & 0.79 & 0.27 & \multirow[b]{2}{*}{ D } & \multirow[b]{2}{*}{0.93} & \multirow[b]{2}{*}{294.00} \\
\hline & 2 & $\left(C_{6} 1 s\right)^{-1}$ & 293.95 & 0.78 & 0.52 & & & \\
\hline \multirow{8}{*}{$\mathrm{N} 1 \mathrm{~s}$} & 2 & $\left(\mathrm{~N}_{9} 1 \mathrm{~s}\right)^{-1}$ & 404.71 & 0.80 & 0.53 & \multirow{4}{*}{ A } & \multirow{4}{*}{1.0} & \multirow{4}{*}{404.85} \\
\hline & 1 & $\left(\mathrm{~N}_{7} 1 \mathrm{~s}\right)^{-1}$ & 404.71 & 0.79 & 0.27 & & & \\
\hline & 2 & $\left(\mathrm{~N}_{3} 1 \mathrm{~s}\right)^{-1}$ & 404.97 & 0.79 & 0.52 & & & \\
\hline & 1 & $\left(\mathrm{~N}_{3} 1 \mathrm{~s}\right)^{-1}$ & 405.27 & 0.80 & 0.27 & & & \\
\hline & 1 & $\left(\mathrm{~N}_{1} 1 \mathrm{~s}\right)^{-1}$ & 406.36 & 0.81 & 0.28 & \multirow{4}{*}{ B } & \multirow{4}{*}{0.99} & \multirow{4}{*}{406.7} \\
\hline & 2 & $\left(\mathrm{~N}_{1} 1 \mathrm{~s}\right)^{-1}$ & 406.48 & 0.81 & 0.54 & & & \\
\hline & 1 & $\left(\mathrm{~N}_{9} 1 \mathrm{~s}\right)^{-1}$ & 406.63 & 0.81 & 0.28 & & & \\
\hline & 2 & $\left(\mathrm{~N}_{7} 1 \mathrm{~s}\right)^{-1}$ & 406.83 & 0.81 & 0.53 & & & \\
\hline \multirow{2}{*}{$\mathrm{O} 1 \mathrm{~s}$} & 1 & $\left(\mathrm{O}_{6} 1 \mathrm{~s}\right)^{-1}$ & 536.76 & 0.80 & 0.27 & \multirow{2}{*}{ A } & & \multirow{2}{*}{537.00} \\
\hline & 2 & $\left(\mathrm{O}_{6} 1 \mathrm{~s}\right)^{-1}$ & 537.03 & 0.80 & 0.53 & & & \\
\hline
\end{tabular}

${ }^{a}$ For easier comparison with experiment, an overall shift was applied to the $\mathrm{ADC}(3)$ ionization energies $(-5.1,-7.8$, and $-10.0 \mathrm{eV}$ for $\mathrm{C} 1 \mathrm{~s}, \mathrm{~N} 1 \mathrm{~s}$ and $\mathrm{O} 1 \mathrm{~s}$ transitions, respectively).
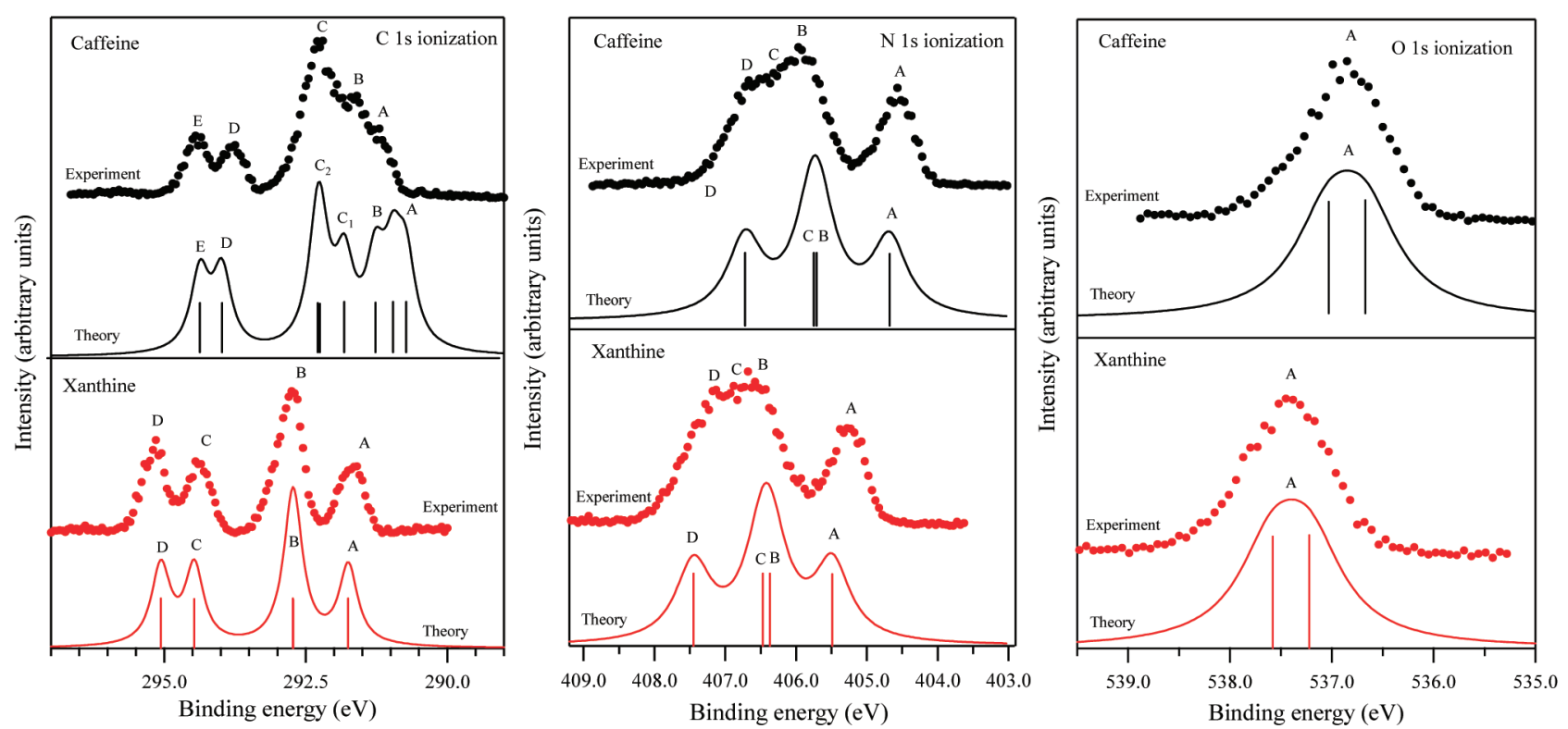

Figure 3. Carbon 1s, nitrogen 1s, and oxygen 1s photoionization spectra of xanthine and caffeine: experiment (points) and theory (ADC(3)/6-31G, full curves). The following parameters were used to generate the theoretical curves: fwhm $=0.4,0.6$, and $0.8 \mathrm{eV}$ for $\mathrm{C} 1 \mathrm{~s}, \mathrm{~N} 1 \mathrm{~s}$, and $\mathrm{O} 1 \mathrm{~s}$ spectra, respectively; shift (caffeine) $=-5.45,-7.9$, and $-9.9 \mathrm{eV}$ for C $1 \mathrm{~s}, \mathrm{~N} 1 \mathrm{~s}$, and $\mathrm{O} 1 \mathrm{~s}$ transitions, respectively; and shift (xanthine) $=-5.45,-7.75$, and $-9.75 \mathrm{eV}$ for $\mathrm{C} 1 \mathrm{~s}, \mathrm{~N} 1 \mathrm{~s}$, and $\mathrm{O} 1 \mathrm{~s}$ transitions, respectively.

Lastly the oxygen spectra show a single peak and the calculated splitting between tautomers is very small, as expected from the fact that the chemical changes occur at the third nearest neighbor. On the other hand, the width of the Hyp O 1 s peak is similar to that of Caff and Xan (Figure 3). Since each of the latter two molecules has two oxygen atoms and Hyp only one, the width of the Hyp O 1s spectrum may be increased by tautomerism, which we have shown above occurs for this compound.

3.2.2. Xanthine and Caffeine. The core level spectra of xanthine and caffeine are shown in Figure 3, and the data are summarized in Table 5. The agreement between the calculated 
Table 5. Energies $\Omega(\mathrm{eV})$, Pole Strengths $P$ of the Vertical C 1s, $\mathrm{N} 1 \mathrm{~s}$, and O 1s Ionization Transitions of Xanthine and Caffeine at the $\operatorname{ADC}(3) / 6-31 G$ Level of Theory in Comparison with the Experimental Data ${ }^{a}$

\begin{tabular}{|c|c|c|c|c|c|}
\hline \multirow{2}{*}{ Molecule } & \multirow{2}{*}{ Transition } & \multicolumn{2}{|l|}{ Theory } & \multicolumn{2}{|c|}{ Experiment } \\
\hline & & $\Omega^{\mathrm{a}}$ & $\mathrm{P}$ & Maximum & $\Omega$ \\
\hline \multirow[t]{5}{*}{ Xanthine } & $\left(C_{5} 1 \mathrm{~s}\right)^{-1}$ & 291.75 & 0.79 & $\mathrm{~A}$ & 291.68 \\
\hline & $\left(\mathrm{C}_{8} 1 \mathrm{~s}\right)^{-1}$ & 292.72 & 0.77 & \multirow[b]{2}{*}{ B } & \\
\hline & $\left(\mathrm{C}_{4} 1 \mathrm{~s}\right)^{-1}$ & 292.73 & 0.79 & & 292.80 \\
\hline & $\left(\mathrm{C}_{6} 1 \mathrm{~s}\right)^{-1}$ & 294.47 & 0.78 & $\mathrm{C}$ & 294.40 \\
\hline & $\left(\mathrm{C}_{2} 1 \mathrm{~s}\right)^{-1}$ & 295.06 & 0.79 & D & 295.18 \\
\hline \multirow[t]{8}{*}{ Caffeine } & $\left(\mathrm{C}_{10} 1 \mathrm{~s}\right)^{-1}$ & 290.73 & 0.80 & $\mathrm{~A}$ & 291.20 \\
\hline & $\left(C_{11} 1 s\right)^{-1}$ & 290.96 & 0.80 & \multirow[b]{2}{*}{ B } & \multirow[b]{2}{*}{291.70} \\
\hline & $\left(\mathrm{C}_{5} 1 \mathrm{~s}\right)^{-1}$ & 291.27 & 0.79 & & \\
\hline & $\left(\mathrm{C}_{12} 1 \mathrm{~s}\right)^{-1}$ & 291.82 & 0.80 & \multirow{3}{*}{$\mathrm{C}$} & \multirow{3}{*}{292.28} \\
\hline & $\left(\mathrm{C}_{8} 1 \mathrm{~s}\right)^{-1}$ & 292.25 & 0.77 & & \\
\hline & $\left(\mathrm{C}_{4} 1 \mathrm{~s}\right)^{-1}$ & 292.29 & 0.78 & & \\
\hline & $\left(\mathrm{C}_{6} 1 \mathrm{~s}\right)^{-1}$ & 293.98 & 0.78 & $\mathrm{D}$ & 293.80 \\
\hline & $\left(C_{2} 1 s\right)^{-1}$ & 294.37 & 0.78 & $\mathrm{E}$ & 294.45 \\
\hline \multirow[t]{4}{*}{ Xanthine } & $\left(\mathrm{N}_{9} 1 \mathrm{~s}\right)^{-1}$ & 405.49 & 0.80 & A & 405.28 \\
\hline & $\left(\mathrm{N}_{1} 1 \mathrm{~s}\right)^{-1}$ & 406.37 & 0.81 & B & 406.44 \\
\hline & $\left(\mathrm{N}_{3} 1 \mathrm{~s}\right)^{-1}$ & 406.47 & 0.81 & $\mathrm{C}$ & 406.83 \\
\hline & $\left(\mathrm{N}_{7} 1 \mathrm{~s}\right)^{-1}$ & 407.45 & 0.81 & $\mathrm{D}$ & 407.35 \\
\hline \multirow[t]{4}{*}{ Caffeine } & $\left(\mathrm{N}_{9} 1 \mathrm{~s}\right)^{-1}$ & 404.68 & 0.80 & A & 404.60 \\
\hline & $\left(\mathrm{N}_{1} 1 \mathrm{~s}\right)^{-1}$ & 405.71 & 0.81 & B & 405.76 \\
\hline & $\left(\mathrm{N}_{3} 1 \mathrm{~s}\right)^{-1}$ & 405.75 & 0.81 & $\mathrm{C}$ & 406.18 \\
\hline & $\left(\mathrm{N}_{7} 1 \mathrm{~s}\right)^{-1}$ & 406.72 & 0.81 & $\mathrm{D}$ & 406.74 \\
\hline \multirow[t]{2}{*}{ Xanthine } & $\left(\mathrm{O}_{2} 1 \mathrm{~s}\right)^{-1}$ & 537.22 & 0.81 & \multirow{2}{*}{ A } & \multirow{2}{*}{537.45} \\
\hline & $\left(\mathrm{O}_{6} 1 \mathrm{~s}\right)^{-1}$ & 537.58 & 0.80 & & \\
\hline \multirow[t]{2}{*}{ Caffeine } & $\left(\mathrm{O}_{6} 1 \mathrm{~s}\right)^{-1}$ & 536.67 & 0.81 & \multirow[t]{2}{*}{ A } & \multirow{2}{*}{536.85} \\
\hline & $\left(\mathrm{O}_{2} 1 \mathrm{~s}\right)^{-1}$ & 537.03 & 0.80 & & \\
\hline
\end{tabular}

${ }^{a}$ For easier comparison with experiment the overall shift was applied to the $\mathrm{ADC}(3)$ ionization energies of caffeine $(-5.45,-7.9$, and $-9.9 \mathrm{eV}$ for $\mathrm{C}$ $1 \mathrm{~s}, \mathrm{~N} 1 \mathrm{~s}$, and $\mathrm{O} 1 \mathrm{~s}$ transitions, respectively) and xanthine $(-5.45,-7.75$, and $-9.75 \mathrm{eV}$ for $\mathrm{C} 1 \mathrm{~s}, \mathrm{~N} 1 \mathrm{~s}$, and $\mathrm{O} 1 \mathrm{~s}$ transitions, respectively).

and experimental C 1s spectra for xanthine is very good, with relative intensities and energy differences being reproduced well. The assignments are given in Table 5, and as for hypoxanthine the order of binding energy follows that expected from electronegativity arguments: $C_{5}$ is bound to only one nitrogen atom; $\mathrm{C}_{8}$ and $\mathrm{C}_{4}$ are bound to two; $\mathrm{C}_{6}$ is bound to oxygen and one nitrogen atom; $\mathrm{C}_{2}$ is in a urea configuration, and bound to one oxygen atom and two nitrogen atoms.

Using the results of the present HF, $\triangle \mathrm{SCF}$ and $\mathrm{ADC}(3)$ calculations in Table 6 one can see that the relaxation and correlation effects for Xan are of the same order as for Hyp. The other observations made for Hyp are also valid here. In particular, it can be seen that the $\mathrm{C} 1 \mathrm{~s}$ spectrum at the $\Delta$ SCF level is again much broader than the experimental one. We note also that there is inversion of the $\left(C_{4}\right)^{-1}$ and $\left(C_{8}\right)^{-1}$ energy levels in the $\mathrm{ADC}(3)$ calculations relative to the $\mathrm{HF}$ and $\Delta S C F / c c-p V T Z$ calculations, which emphasizes the importance of the electron correlation effects for these transitions.

The substitution of three hydrogen atoms by methyl groups to give caffeine adds new features to the $\mathrm{C} 1 \mathrm{~s}$ spectrum. The calculations correctly predict the overall shift of the core hole states to lower binding energies. The agreement is less good for the description of the energies of these new states. More specifically, the distribution of the spectral intensity within the $\mathrm{ABC}$ band is not reproduced by the present calculations. This band includes contributions of the three methyl groups (atoms
Table 6. Vertical C 1s, N 1s, and O 1s Ionization Energies (eV) of Xanthine Calculated at the Hartree-Fock (Koopmans' Theorem), $\triangle \mathrm{SCF}$, and $\mathrm{ADC}(3)$ Levels of Theory Using 6-31G and cc-pVTZ Basis Sets ${ }^{a}$

\begin{tabular}{|c|c|c|c|c|c|}
\hline \multirow[b]{2}{*}{ transition } & \multicolumn{2}{|c|}{ Koopmans' } & \multicolumn{2}{|c|}{$\Delta \mathrm{SCF}$} & \multirow{2}{*}{$\frac{\mathrm{ADC}(3)}{6-31 \mathrm{G}}$} \\
\hline & $6-31 \mathrm{G}$ & cc-pVTZ & $6-31 \mathrm{G}$ & cc-pVTZ & \\
\hline & 307.64 & 306.96 & 294.02 & 291.74 & 297.20 \\
\hline$\left(C_{5} 1 s\right)^{-1}$ & 0.0 & 0.0 & 0.0 & 0.0 & 0.0 \\
\hline$\left(C_{8} 1 s\right)^{-1}$ & 1.63 & 1.90 & 1.59 & 1.77 & 0.97 \\
\hline$\left(C_{4} 1 s\right)^{-1}$ & 1.49 & 1.65 & 1.60 & 1.73 & 0.98 \\
\hline$\left(C_{6} 1 s\right)^{-1}$ & 3.05 & 2.91 & 3.93 & 3.75 & 2.72 \\
\hline \multirow[t]{2}{*}{$\left(C_{2} 1 s\right)^{-1}$} & 3.76 & 3.63 & 4.92 & 4.81 & 3.31 \\
\hline & 424.73 & 424.14 & 407.87 & 405.37 & 413.24 \\
\hline$\left(\mathrm{N}_{9} 1 \mathrm{~s}\right)^{-1}$ & 0.0 & 0.0 & 0.0 & 0.0 & 0.0 \\
\hline$\left(\mathrm{N}_{1} 1 \mathrm{ls}\right)^{-1}$ & 0.82 & 1.01 & 1.08 & 1.31 & 0.88 \\
\hline$\left(\mathrm{N}_{3} 1 \mathrm{ls}\right)^{-1}$ & 0.97 & 1.22 & 1.23 & 1.54 & 0.98 \\
\hline \multirow[t]{2}{*}{$\left(\mathrm{N}_{7} 1 \mathrm{~s}\right)^{-1}$} & 1.77 & 1.93 & 1.89 & 2.08 & 1.96 \\
\hline & 559.41 & 558.84 & 539.51 & 537.00 & 546.97 \\
\hline$\left(\mathrm{O}_{2} 1 \mathrm{~s}\right)^{-1}$ & 0.0 & 0.0 & 0.0 & 0.0 & 0.0 \\
\hline$\left(\mathrm{O}_{6} 1 \mathrm{~s}\right)^{-1}$ & 0.24 & 0.16 & -0.17 & -0.24 & 0.36 \\
\hline
\end{tabular}

${ }^{a}$ Relative ionization energies with respect to the $\left(\mathrm{C}_{5} 1 \mathrm{~s}\right)^{-1},\left(\mathrm{~N}_{9} 1 \mathrm{~s}\right)^{-1}$, and $\left(\mathrm{O}_{2} 1 \mathrm{~s}\right)^{-1}$ states are given (the absolute ionization energies for these states are shown in the lines preceding transitions of each type). 
$\mathrm{C}_{10}, \mathrm{C}_{11}$, and $\mathrm{C}_{12}$ ), and is subject to conformational effects due to the internal rotation of the methyl groups. Only the most stable conformer of caffeine (Figure 1B) was considered in our calculations, so the present theoretical spectrum is only approximate, and may miss contributions due to the other possible rotamers. Our preliminary study however indicates that the methyl groups' rotations do not appreciably influence the shape of the $\mathrm{C}$ 1s spectra. The reasons for the disagreement with experiment should therefore be insufficient basis set quality or effects beyond the scope of the present electronic structure calculations, such as nonadiabatic nuclear dynamics. The latter is known to be important for valence electron excitations in caffeine. ${ }^{33}$

As can be seen from the HF and $\triangle$ SCF results in Table 7, the energy of the $\left(C_{5}\right)^{-1}$ transition, contributing to the lowest $C 1 \mathrm{~s}$

Table 7. Vertical C 1s, N 1s, and $\mathrm{O}$ 1s Ionization Energies $(\mathrm{eV})$ of Caffeine Calculated at the Hartree-Fock (Koopmans' Theorem), $\Delta S C F$, and ADC(3) Levels of Theory Using 6-31G and cc-pVTZ Basis Sets ${ }^{a}$

\begin{tabular}{|c|c|c|c|c|c|}
\hline \multirow[b]{2}{*}{ transition } & \multicolumn{2}{|c|}{ Koopmans' } & \multicolumn{2}{|c|}{$\Delta \mathrm{SCF}$} & \multirow{2}{*}{$\begin{array}{c}\mathrm{ADC}(3) \\
6-31 \mathrm{G}\end{array}$} \\
\hline & $6-31 G$ & cc-pVTZ & $6-31 G$ & cc-pVTZ & \\
\hline & 306.35 & 306.16 & 293.66 & 291.75 & 296.18 \\
\hline$\left(C_{10} 1 s\right)^{-1}$ & 0.0 & 0.0 & 0.0 & 0.0 & 0.0 \\
\hline$\left(C_{11} 1 s\right)^{-1}$ & 0.28 & 0.37 & 0.25 & 0.36 & 0.23 \\
\hline$\left(C_{5} 1 s\right)^{-1}$ & 0.83 & 0.39 & -0.25 & -0.59 & 0.54 \\
\hline$\left(C_{12} 1 s\right)^{-1}$ & 1.07 & 1.03 & 1.08 & 1.05 & 1.09 \\
\hline$\left(C_{8} 1 s\right)^{-1}$ & 2.50 & 2.29 & 1.33 & 1.14 & 1.52 \\
\hline$\left(\mathrm{C}_{4} 1 \mathrm{~s}\right)^{-1}$ & 2.37 & 2.09 & 1.38 & 1.17 & 1.56 \\
\hline$\left(\mathrm{C}_{6} 1 \mathrm{~s}\right)^{-1}$ & 3.94 & 3.36 & 3.65 & 3.16 & 3.25 \\
\hline \multirow[t]{2}{*}{$\left(C_{2} 1 s\right)^{-1}$} & 4.49 & 3.95 & 4.35 & 3.96 & 3.64 \\
\hline & 424.30 & 423.78 & 407.27 & 404.80 & 412.58 \\
\hline$\left(\mathrm{N}_{9} 1 \mathrm{~s}\right)^{-1}$ & 0.0 & 0.0 & 0.0 & 0.0 & 0.0 \\
\hline$\left(\mathrm{N}_{1} 1 \mathrm{~s}\right)^{-1}$ & 1.04 & 1.19 & 1.01 & 1.24 & 1.03 \\
\hline$\left(\mathrm{N}_{3} 1 \mathrm{~s}\right)^{-1}$ & 1.11 & 1.32 & 1.09 & 1.41 & 1.07 \\
\hline \multirow[t]{2}{*}{$\left(\mathrm{N}_{7} 1 \mathrm{~s}\right)^{-1}$} & 1.96 & 2.07 & 1.81 & 1.99 & 2.04 \\
\hline & 559.27 & 558.67 & 538.82 & 536.27 & 546.57 \\
\hline$\left(\mathrm{O}_{6} 1 \mathrm{~s}\right)^{-1}$ & 0.0 & 0.0 & 0.0 & 0.0 & 0.0 \\
\hline$\left(\mathrm{O}_{2} 1 \mathrm{~s}\right)^{-1}$ & -0.23 & -0.12 & 0.10 & 0.20 & 0.36 \\
\hline
\end{tabular}

${ }^{a}$ Relative ionization energies with respect to the $\left(\mathrm{C}_{10} 1 \mathrm{~s}\right)^{-1},\left(\mathrm{~N}_{9} 1 \mathrm{~s}\right)^{-1}$, and $\left(\mathrm{O}_{6} 1 \mathrm{~s}\right)^{-1}$ states are given (the absolute ionization energies for these states are shown in the lines preceding transitions of each type).

ionization band of Caff, is indeed rather sensitive toward the basis set size. Moreover, for this transition an unusually large difference between the HF and $\triangle S C F$ ionization energies can be seen. Consequently, the $\left(\mathrm{C}_{5}\right)^{-1}$ transition is predicted by $\triangle$ SCF to be the lowest one, while at the Koopmans' and $\mathrm{ADC}(3)$ level of theory it is only the third lowest one in the $\mathrm{C}$ 1s spectrum. Large relaxation shifts can be seen also for the $\left(\mathrm{C}_{4}\right)^{-1}$ and $\left(\mathrm{C}_{8}\right)^{-1}$ transitions. This has obviously to do with the somewhat special role of the $\mathrm{C}_{5}, \mathrm{C}_{4}$, and $\mathrm{C}_{8}$ sites of the Caff molecule, which are strongly involved in various intramolecular interactions and subject to conjugation and inductive effects. For these transitions also an increased role of electron correlation can be expected, so that the correct spectral profile can be predicted only by treating the interplay of the relaxation and correlation effects in a highly balanced manner, that is to a good extent attained in the case of the present Green's function ADC methods. The width of the $\mathrm{C} 1 \mathrm{~s}$ spectrum of Caff is (as for Hyp) substantially overestimated at the $\triangle$ SCF level, the correspondence being much better at the $\operatorname{ADC}(3)$ level.
The nitrogen 1s spectra of xanthine and caffeine are shown in Figure 3. The gross features are reproduced, i.e. there are at least three peaks, but it appears that the calculations do not reproduce the relative energies of the higher binding energy peaks. In particular the splitting of the peaks due to ionization of $\mathrm{N}_{1}$ and $\mathrm{N}_{3}$ is calculated to be 0.1 or $0.04 \mathrm{eV}$ in xanthine and caffeine, respectively, but fitting of the peaks gives an estimated splitting of about $0.4 \mathrm{eV}$.

In Caff, the splitting is also very small at the HF/6-31G and $\Delta \mathrm{SCF} / 6-31 \mathrm{G}$ levels of theory, but it increases up to $0.2 \mathrm{eV}$ as the basis set is extended (Table $4 \mathrm{~b}$ ). A more flexible description of the electronic density including polarization functions here is apparently required to reproduce correctly the $\mathrm{N} 1 \mathrm{~s}$ ionization spectrum. We made a similar observation earlier in the case of the $\mathrm{N} 1 \mathrm{~s}$ excitation spectrum of uracil. ${ }^{44}$ In Xan, the extension of the basis set also tends to split the two central lines in the $\mathrm{N}$ 1s spectrum more strongly (Table 4a), though this is not so pronounced as in Caff. The account of the ground and finalstate electron correlation at the $\mathrm{ADC}(3) / 6-31 \mathrm{G}$ level of theory, on the contrary, moves the $\left(\mathrm{N}_{1} 1 \mathrm{~s}\right)^{-1}$ and $\left(\mathrm{N}_{3} 1 \mathrm{~s}\right)^{-1}$ lines in both molecules closer together compared to the uncorrelated $\mathrm{HF}$ and $\triangle \mathrm{SCF}$ treatments.

The imino nitrogen atom $\mathrm{N}_{9}$ has the lowest binding energy in both species, as expected. However the order of binding energy of the amino nitrogen atoms is then $\mathrm{N}_{1}<\mathrm{N}_{3}<\mathrm{N}_{7}$, the reverse of the order expected by considering the distance to the nearby oxygen atoms. No nitrogen atom is bound directly to oxygen, but $\mathrm{N}_{1}$ has two oxygen atoms located at second nearest neighbor positions, $\mathrm{N}_{3}$ has one, and $\mathrm{N}_{7}$ has none. From initial state charge transfer (or inductive) arguments, the binding energy order is expected to be $\mathrm{N}_{1}>\mathrm{N}_{3}>\mathrm{N}_{7}$. Provided the accuracy of our calculations is sufficient to correctly predict the relative position of these three transitions in a narrow energy interval of about $1 \mathrm{eV}$, this trend implies that resonance effects dominate the direct inductive effects, ${ }^{68}$ and indeed, the $\mathrm{N}_{1}$ and $\mathrm{N}_{3}$ atoms are located in ortho and para positions with respect to the oxygen atoms, as required for resonance effects. This points to a significant degree of conjugation between $\mathrm{N}_{1}, \mathrm{~N}_{3}$, and the oxygen atoms, even though the 6-membered ring contains only one formal double bond.

The $\mathrm{O}$ 1s spectra in Figure 3 show that although the core levels of the two oxygen atoms differ in energy by $0.36 \mathrm{eV}$ theoretically, the difference is too small to be resolved experimentally. The maximum of the spectrum of caffeine is at $0.6 \mathrm{eV}$ lower binding energy than that of xanthine, almost the same value as the shift of the $\mathrm{N} 1 \mathrm{~s}$ spectrum, $0.66 \mathrm{eV}$. The average shift of the $\mathrm{C} 1 \mathrm{~s}$ spectrum is more difficult to evaluate due to the appearance of two new peaks, but the average shift of the $\mathrm{C}_{5}$ and $\mathrm{C}_{2} 1 \mathrm{~s}$ core levels (these atoms are present in both species) is $0.6 \mathrm{eV}$. This nearly uniform shift of the carbon, nitrogen and oxygen core levels of about $0.6 \mathrm{eV}$ in methylamine implies that the shift is most likely due to final state screening effects by the additional methyl groups.

3.2. Core Level Photoabsorption. The X-ray photoabsorption spectra of xanthine, hypoxanthine, and caffeine are presented in Figure $4 a-c$ and Table 8 . In Table 8 , only the measured band maxima are shown together with their assignment in terms of the strongest transitions, as predicted by the present $\operatorname{ADC}(2)$ calculations. The complete list of the calculated excitation energies and intensities for the vertical core-level transitions of Hyp, Xan, and Caf together with the assignment of the observed bands is available as Supporting Information. The electronic structure of the present com- 


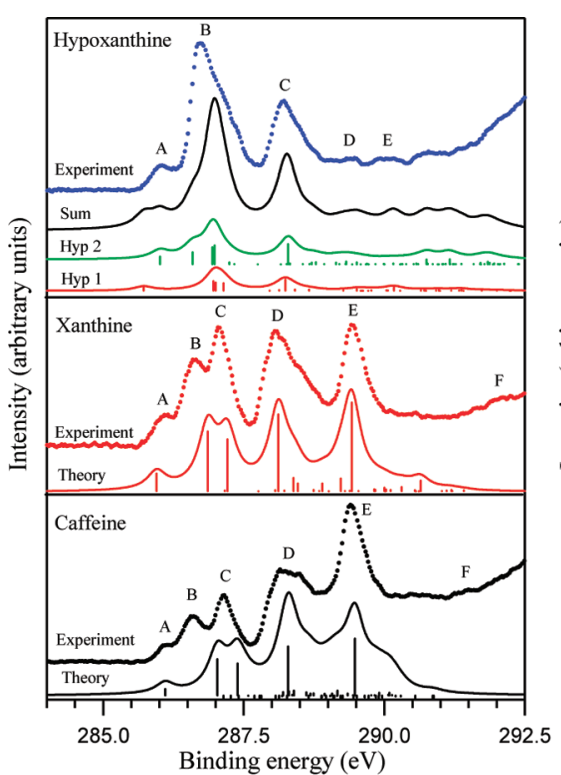

(a)

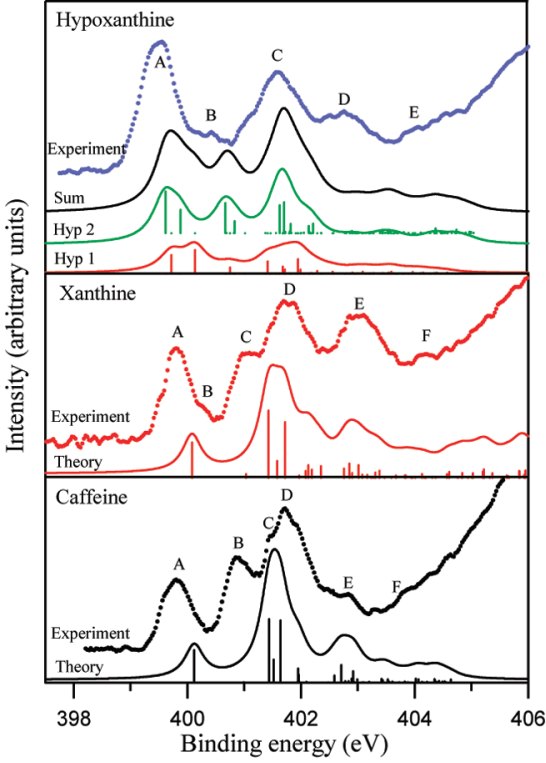

(b)

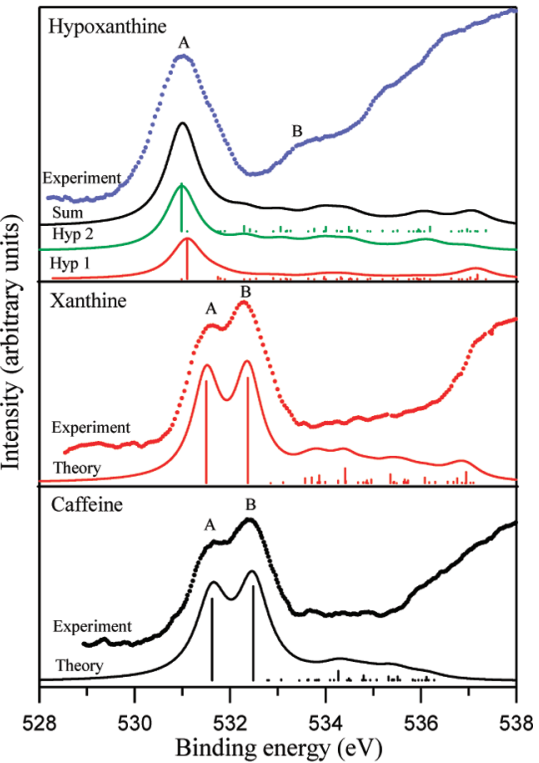

(c)

Figure 4. (a) Carbon 1s, (b) nitrogen 1s, and (c) oxygen 1s photoabsorption spectra of hypoxanthine, xanthine, and caffeine: experiment (points) and theory $(\mathrm{ADC}(2) / 6-31+\mathrm{G}$, full curves) The following parameters were used to generate the theoretical curves: for $\mathrm{C} 1 \mathrm{~s}, \mathrm{fwhm}=0.4 \mathrm{eV}$, shift $=$ $-5.2,-5.3$, and $-5.1 \mathrm{eV}$ for hypoxanthine, xanthine, and caffeine, respectively; for $\mathrm{N} 1 \mathrm{~s}$, fwhm $=0.4 \mathrm{eV}$, shift $=-4.4,-4.4$, and $-4.3 \mathrm{eV}$ for hypoxanthine, xanthine, and caffeine, respectively; for $\mathrm{O} 1 \mathrm{~s}$, fwhm $=0.8 \mathrm{eV}$, shift $=-4.4,-3.85$, and $-3.75 \mathrm{eV}$ for hypoxanthine, xanthine, and caffeine, respectively.

pounds is closely related to guanine, and like guanine, all tautomers of these molecules have four unoccupied antibonding orbitals of $\pi$ character, or $a^{\prime \prime}$ character in $C_{s}$ symmetry, ${ }^{42}$ which give rise to four valence-type excited states, referred to as $\mathrm{V}_{1}$ to $\mathrm{V}_{4}$.

The C 1s NEXAFS spectra of the samples in the 284-290 $\mathrm{eV}$ energy range have a complex band structure with the maxima labeled A-F, Figure 4a. The $\mathrm{C}$ 1s photoabsorption spectrum of hypoxanthine is dominated by two strong peaks $\mathrm{B}$ and $\mathrm{C}$ at 286.73 and $288.22 \mathrm{eV}$, respectively, and also shows two less pronounced features D and E at 289.4 and $290.0 \mathrm{eV}$, respectively. The experimental and calculated spectra of guanine $^{42}$ are very similar to the experimental spectra for Hyp. As in our previous results, ${ }^{40}$ the first maximum $A$ is due to the $\mathrm{C}_{5} 1 \mathrm{~s} \rightarrow \mathrm{V}_{1}$ transition and the present calculations give the same assignment. This site is relatively weakly perturbed by chemical changes between adenine, guanine and hypoxanthine. The next band $\mathrm{B}$ at $286.73 \mathrm{eV}$ is formed by three transitions of $\mathrm{C}_{4}, \mathrm{C}_{8}$ and $\mathrm{C}_{2} 1 \mathrm{~s} \rightarrow \mathrm{V}_{1}$, and both tautomers contribute. Our calculations also predict here the onset of Rydberg series. The final state of the most intense of these transitions $\mathrm{C}_{5} 1 \mathrm{~s} \rightarrow \mathrm{V}_{2}$ / $3 p$ contributing on the high energy side of band $B$ could not be clearly assigned in our calculations, and it might be of mixed Rydberg/valence character (see Supporting Information). Adenine and guanine have resonances at $287.4 \mathrm{eV}^{40}$ and $287.3 \mathrm{eV}^{42}$ respectively, but the states contributing to those resonances seem to have shifted in energy, leaving only a slight shoulder on the high energy side of peak $\mathrm{B}$. Band $\mathrm{C}$ is essentially due to $\mathrm{C}_{6} 1 \mathrm{~s} \rightarrow \mathrm{V}_{1}$ transitions from both tautomers. According to our calculations, several moderately strong transitions of valence, Rydberg and mixed Rydberg/valence character contribute to band $\mathrm{C}$ at higher energy (e.g., $\mathrm{C}_{5} 1 \mathrm{~s} \rightarrow$ $\mathrm{V}_{3}$ and $\mathrm{C}_{8} 1 \mathrm{~s} \rightarrow 3 \mathrm{~s}$ ). Band $\mathrm{D}$ is due to a complex mixture of valence and Rydberg transitions from $\mathrm{C}_{4}, \mathrm{C}_{2}$ and $\mathrm{C}_{8}$ 1s core levels. The low intensity maximum $\mathrm{E}$ near the region of ionization thresholds is formed by the various $\mathrm{C}_{5}, \mathrm{C}_{8}$ and $\mathrm{C}_{2}$ 1s $\rightarrow$ Rydberg transitions. ${ }^{40}$ Finally the broad resonances at higher photon energy range $(292-305 \mathrm{eV})$ are due to transitions to $\sigma^{*}$ states. These are in the continuum and the present computational scheme does not include continuum states.

The C 1s photoabsorption spectra of xanthine and caffeine look very similar to one another with the main difference lying in changes in relative peak intensity. The first three peaks A-C in the C 1s NEXAFS spectra of xanthine and caffeine are very close in energy and have similar relative intensities, and we assign them to the same resonances. The peaks $\mathrm{A}, \mathrm{B}, \mathrm{C}$ and $\mathrm{D}$ are dominated by transitions to $\mathrm{V}_{1}$ from $\mathrm{C}_{5}, \mathrm{C}_{8}, \mathrm{C}_{4}$, and $\mathrm{C}_{6}$, respectively. There are many other states present, but these are much weaker than the main transition (see Supporting Information). Caffeine has three additional methyl carbon atoms $\left(\mathrm{C}_{10}, \mathrm{C}_{11}\right.$, and $\left.\mathrm{C}_{12}\right)$, and according to our calculations the $\mathrm{CH}_{3}$ 1s $\rightarrow 3 \mathrm{p}$ transitions contribute to peak $\mathrm{D}$. The lowest of the methyl group transitions with appreciable intensity according to our calculations is the $\mathrm{C}_{12} 1 \mathrm{~s} \rightarrow 3 \mathrm{~s}$ transition, contributing to band $\mathrm{C}$. The conspicuous peak E of Xan and Caff, which was not observed for hypoxanthine, corresponds mainly to excitations of the second carbonyl carbon atom $\mathrm{C}_{2} 1 \mathrm{~s}$ $\rightarrow \mathrm{V}_{1}$ resonance. Another prominent excitation among various transitions contributing to peak $\mathrm{E}$ is $\mathrm{C}_{4} 1 \mathrm{~s} \rightarrow \mathrm{V}_{2}$.

For the nitrogen $\mathrm{K}$ edge, the agreement of the theoretical spectral profiles with experiment is poorer, and the reasons for this have been discussed elsewhere. ${ }^{44}$ The density of interacting core excited states is rather high, making the results sensitive to basis set selection and the level of theory. The calculated individual transitions however give a qualitatively correct picture and can be used for assignment of the observed spectra. The $\mathrm{N}$ 1s NEXAFS spectra of Xan, Hyp, and Caff are shown in Figure $4 \mathrm{~b}$ and the energies of the observed resonances are summarized in Table 8 . The nitrogen edge photoabsorption spectrum of hypoxanthine is characterized by 
Table 8. Energies of Peaks $(\mathrm{eV}) \pm 0.1 \mathrm{eV}$ in the NEXAFS Spectra and Their Assignments Based on the Present ADC(2) Calculations in Terms of the Strongest Transitions Contributing to the Given Peak ${ }^{a}$

\begin{tabular}{|c|c|c|c|c|c|c|c|c|}
\hline \multicolumn{3}{|r|}{ hypoxanthine } & \multicolumn{3}{|c|}{ xanthine } & \multicolumn{3}{|c|}{ caffeine } \\
\hline edge & energy & assignment & edge & energy & assignment & edge & energy & assignment \\
\hline \multirow[t]{18}{*}{$\mathrm{C} 1 \mathrm{~s}$} & $286.05(\mathrm{~A})$ & $\mathrm{C}_{5} 1 \mathrm{~s} \rightarrow \mathrm{V}_{1}(\mathrm{~T} 1, \mathrm{~T} 2)$ & C 1 s & $286.11(\mathrm{~A})$ & $\mathrm{C}_{5} 1 \mathrm{~s} \rightarrow \mathrm{V}_{1}$ & C $1 \mathrm{~s}$ & $286.10(\mathrm{~A})$ & $\mathrm{C}_{5} \rightarrow \mathrm{V}_{1}$ \\
\hline & $286.73(\mathrm{~B})$ & $\mathrm{C}_{4}, \mathrm{C}_{8}, \mathrm{C}_{2} 1 \mathrm{~s} \rightarrow \mathrm{V}_{1}(\mathrm{~T} 1, \mathrm{~T} 2)$ & & 286.59 (B) & $\mathrm{C}_{8} 1 \mathrm{~s} \rightarrow \mathrm{V}_{1}$ & & $286.58(\mathrm{~B})$ & $\mathrm{C}_{8} \rightarrow \mathrm{V}_{1}$ \\
\hline & $288.22(\mathrm{C})$ & $\mathrm{C}_{6} 1 \mathrm{~s} \rightarrow \mathrm{V}_{1}(\mathrm{~T} 1, \mathrm{~T} 2)$ & & $287.07(\mathrm{C})$ & $\mathrm{C}_{5} 1 \mathrm{~s} \rightarrow 3 \mathrm{~s}$ & & $287.12(\mathrm{C})$ & $\mathrm{C}_{4} \rightarrow \mathrm{V}_{1}$ \\
\hline & $289.4(\mathrm{D})$ & $\mathrm{C}_{4} 1 \mathrm{~s} \rightarrow 3 \mathrm{p} / \mathrm{V}_{2} ?(\mathrm{~T} 2)$ & & & $\mathrm{C}_{4} 1 \mathrm{~s} \rightarrow \mathrm{V}_{1}$ & & $288.32(\mathrm{D})$ & $\mathrm{C}_{6} \rightarrow \mathrm{V}_{1}$ \\
\hline & & $\mathrm{C}_{2} 1 \mathrm{~s} \rightarrow 3 \mathrm{~s}(\mathrm{~T} 2, \mathrm{~T} 1)$ & & $288.05(\mathrm{D})$ & $\mathrm{C}_{6} 1 \mathrm{~s} \rightarrow \mathrm{V}_{1}$ & & $289.40(\mathrm{E})$ & $\mathrm{C}_{2} \rightarrow \mathrm{V}_{1}$ \\
\hline & & $\mathrm{C}_{4} 1 \mathrm{~s} \rightarrow \mathrm{V}_{3}(\mathrm{~T} 2)$ & & & $\mathrm{C}_{5} 1 \mathrm{~s} \rightarrow \mathrm{V}_{2} / 3 \mathrm{p} ?$ & & $291.47(\mathrm{~F})$ & Rydberg states \\
\hline & & $\mathrm{C}_{8} 1 \mathrm{~s} \rightarrow 3 \mathrm{p}(\mathrm{T} 2)$ & & & $\mathrm{C}_{5} 1 \mathrm{~s} \rightarrow \mathrm{V}_{3}$ & & 296.07 & $\sigma^{*}$ shape \\
\hline & & $\mathrm{C}_{8} 1 \mathrm{~s} \rightarrow \mathrm{V}_{2} / 3 \mathrm{p} ?(\mathrm{~T} 2)$ & & $289.45(\mathrm{E})$ & $\mathrm{C}_{2} 1 \mathrm{~s} \rightarrow \mathrm{V}_{1}$ & & 303.90 & resonances \\
\hline & $290.00(\mathrm{E})$ & $\mathrm{C}_{5} 1 \mathrm{~s} \rightarrow \mathrm{V}_{4} / 5 \mathrm{p} ?(\mathrm{~T} 1, \mathrm{~T} 2)$ & & $292.08(\mathrm{~F})$ & Rydberg states & & & \\
\hline & & $\mathrm{C}_{8} 1 \mathrm{~s} \rightarrow \mathrm{V}_{3} / 4 \mathrm{p} ?(\mathrm{~T} 2)$ & & & & & & \\
\hline & & $\mathrm{C}_{2} 1 \mathrm{~s} \rightarrow 3 \mathrm{p} / \mathrm{V}_{2} ?(\mathrm{~T} 2)$ & & & & & & \\
\hline & 294.35 & $\sigma^{*}$ shape resonances & & 296.15 & $\begin{array}{l}\sigma^{*} \text { shape } \\
\text { resonances }\end{array}$ & & & \\
\hline & 304.05 & & & 303.44 & & & & \\
\hline & 291.40 & $\mathrm{IP}, \mathrm{C}_{5}$ & & 291.68 & $\mathrm{IP}, \mathrm{C}_{5}$ & & 291.20 & $\mathrm{C}_{10}$ \\
\hline & 292.25 & IP, $\mathrm{C}_{4}, \mathrm{C}_{8}$ & & 292.80 & IP, $\mathrm{C}_{4}, \mathrm{C}_{8}$ & & 291.70 & $\mathrm{C}_{11}, \mathrm{C}_{5}$ \\
\hline & 292.82 & $\mathrm{IP}, \mathrm{C}_{2}$ & & 294.40 & $\mathrm{IP}, \mathrm{C}_{6}$ & & 292.28 & $\mathrm{C}_{4}, \mathrm{C}_{8}, \mathrm{C}_{12}$ \\
\hline & 294.00 & IP, $\mathrm{C}_{6}$ & & 295.18 & $\mathrm{IP}, \mathrm{C}_{2}$ & & 293.80 & $\mathrm{C}_{6}$ \\
\hline & & & & & & & 294.45 & $\mathrm{C}_{2}$ \\
\hline \multirow[t]{26}{*}{$\mathrm{N}$ 1s } & $399.52(\mathrm{~A})$ & $\mathrm{N}_{3} 1 \mathrm{~s} \rightarrow \mathrm{V}_{1}(\mathrm{~T} 2$ and $\mathrm{T} 1)$ & $\mathrm{N}$ 1s & 399.80 (A) & $\mathrm{N}_{9} 1 \mathrm{~s} \rightarrow \mathrm{V}_{1}$ & $\mathrm{~N}$ 1s & $399.80(\mathrm{~A})$ & $\mathrm{N}_{9} \rightarrow \mathrm{V}_{1}$ \\
\hline & $400.42(\mathrm{~B})$ & $\mathrm{N}_{9} 1 \mathrm{~s} \rightarrow \mathrm{V}_{1}(\mathrm{~T} 2)$ & & $400.28(\mathrm{~B})$ & - & & 400.88 (B) & $\mathrm{N}_{9} \rightarrow \mathrm{V}_{2} / 3 \mathrm{p} ?$ \\
\hline & & $\mathrm{N}_{7} 1 \mathrm{~s} \rightarrow \mathrm{V}_{1}(\mathrm{~T} 1)$ & & $401.00(\mathrm{C})$ & $\mathrm{N}_{9} 1 \mathrm{~s} \rightarrow \mathrm{V}_{2}$ & & $401.45(\mathrm{C})$ & $\mathrm{N}_{1} \rightarrow \mathrm{V}_{1}$ \\
\hline & & $\mathrm{N}_{9} 1 \mathrm{~s} \rightarrow \mathrm{V}_{2} / 3 \mathrm{p} ?(\mathrm{~T} 2)$ & & $401.78(\mathrm{D})$ & $\mathrm{N}_{7} 1 \mathrm{~s} \rightarrow \mathrm{V}_{1}$ & & $401.72(\mathrm{D})$ & $\mathrm{N}_{7} \rightarrow \mathrm{V}_{1}$ \\
\hline & & $\mathrm{N}_{7} 1 \mathrm{~s} \rightarrow 3 \mathrm{p} / \mathrm{V}_{2} ?(\mathrm{~T} 1)$ & & & $\mathrm{N}_{1}, \mathrm{~N}_{3}, \mathrm{~N}_{7}, \mathrm{~N}_{9}$ & & $402.86(\mathrm{E})$ & $\mathrm{N}_{3} \rightarrow \mathrm{V}_{2}$ \\
\hline & $401.59(\mathrm{C})$ & $\mathrm{N}_{3} 1 \mathrm{~s} \rightarrow \mathrm{V}_{2} / 3 \mathrm{p} ?(\mathrm{~T} 2)$ & & $403.01(\mathrm{E})$ & $1 \mathrm{~s} \rightarrow \mathrm{V}_{2}, \mathrm{~V}_{3}$ & & $403.50(\mathrm{~F})$ & Rydbergs \\
\hline & & $\mathrm{N}_{1} 1 \mathrm{~s} \rightarrow \mathrm{V}_{1}(\mathrm{~T} 1)$ & & & Rydbergs & & 407.45 & $\begin{array}{l}\sigma^{*} \text { shape } \\
\text { resonance }\end{array}$ \\
\hline & & $\mathrm{N}_{1} 1 \mathrm{~s} \rightarrow \mathrm{V}_{1}(\mathrm{~T} 2)$ & & $404.18(\mathrm{~F})$ & $\mathrm{N} 1 \mathrm{~s} \rightarrow \mathrm{V}_{3}, \mathrm{~V}_{4}$ & & & \\
\hline & & $\mathrm{N}_{7} 1 \mathrm{~s} \rightarrow \mathrm{V}_{1}(\mathrm{~T} 2)$ & & & Rydbergs & & & \\
\hline & & $\mathrm{N}_{1} 1 \mathrm{~s} \rightarrow 3 \mathrm{~s}(\mathrm{~T} 2)$ & & & & & & \\
\hline & & $\mathrm{N}_{9} 1 \mathrm{~s} \rightarrow \mathrm{V}_{1}(\mathrm{~T} 1)$ & & 407.30 & $\sigma^{*}$ shape resonance & & & \\
\hline & & $\mathrm{N}_{9} 1 \mathrm{~s} \rightarrow \mathrm{V}_{3} / 4 \mathrm{p} ?(\mathrm{~T} 2)$ & & & & & & \\
\hline & & $\mathrm{N}_{3} 1 \mathrm{~s} \rightarrow \mathrm{V}_{3} / 4 \mathrm{p} ?(\mathrm{~T} 2)$ & & & & & & \\
\hline & $402.76(\mathrm{D})$ & $\mathrm{N}_{3} 1 \mathrm{~s} \rightarrow \mathrm{V}_{2} / 4 \mathrm{p} ?(\mathrm{~T} 1)$ & & & & & & \\
\hline & & $\mathrm{N}_{1} 1 \mathrm{~s} \rightarrow 3 \mathrm{p}(\mathrm{T} 2)$ & & & & & & \\
\hline & & $\mathrm{N}_{7} 1 \mathrm{~s} \rightarrow 3 \mathrm{p}(\mathrm{T} 2)$ & & & & & & \\
\hline & & $\mathrm{N}_{9} 1 \mathrm{~s} \rightarrow \mathrm{V}_{2} / 3 \mathrm{p} ?(\mathrm{~T} 1)$ & & & & & & \\
\hline & & $\mathrm{N}_{7} 1 \mathrm{~s} \rightarrow 4 \mathrm{~s}(\mathrm{~T} 2)$ & & & & & & \\
\hline & & $\mathrm{N}_{9} 1 \mathrm{~s} \rightarrow \mathrm{V}_{3} / 4 \mathrm{p} ?(\mathrm{~T} 1)$ & & & & & & \\
\hline & & $\mathrm{N}_{7} 1 \mathrm{~s} \rightarrow 4 \mathrm{p} / \mathrm{V}_{2} ?(\mathrm{~T} 2)$ & & & & & & \\
\hline & $403.96(\mathrm{E})$ & $\mathrm{N}_{7} 1 \mathrm{~s} \rightarrow 4 \mathrm{p}(\mathrm{T} 2)$ & & & & & & \\
\hline & 408.25 & $\sigma^{*}$ shape resonance & & & & & & \\
\hline & 404.85 & IP, $\mathrm{N}_{3}, \mathrm{~N}_{9}$ & & 405.28 & $\mathrm{IP}, \mathrm{N}_{3}$ & & 404.60 & IP, $\mathrm{N}_{9}$ \\
\hline & 406.55 & IP, $\mathrm{N}_{7}$ & & 406.44 & $\mathrm{~N}_{9}$ & & 405.76 & IP, $\mathrm{N}_{3}-\mathrm{CH}_{3}$ \\
\hline & 406.83 & IP, $\mathrm{N}_{1}$ & & 406.83 & IP, $\mathrm{N}_{7}$ & & 406.18 & IP, $\mathrm{N}_{1}-\mathrm{CH}_{3}$ \\
\hline & & & & 407.35 & IP, $\mathrm{N}_{1}$ & & 406.74 & IP, $\mathrm{N}_{7}-\mathrm{CH}_{3}$ \\
\hline \multirow[t]{4}{*}{ O $1 \mathrm{~s}$} & $530.95(\mathrm{~A})$ & $\mathrm{O} 1 \mathrm{~s} \rightarrow \mathrm{V}_{1}(\mathrm{~T} 2, \mathrm{~T} 1)$ & O 1s & $531.59(\mathrm{~A})$ & $\mathrm{O}_{6} \rightarrow \mathrm{V}_{1}$ & O 1s & $531.65(\mathrm{~A})$ & $\mathrm{O}_{6} \rightarrow \mathrm{V}_{1}$ \\
\hline & $533.62(\mathrm{~B})$ & & & $532.29(\mathrm{~B})$ & $\mathrm{O}_{2} \rightarrow \mathrm{V}_{1}$ & & $532.43(\mathrm{~B})$ & $\mathrm{O}_{2} \rightarrow \mathrm{V}_{1}$ \\
\hline & 539.53 & $\begin{array}{l}\text { Rydberg and antibonding states } \sigma^{*} \text { shape } \\
\text { resonance }\end{array}$ & & 538.73 & $\sigma^{*}$ shape resonance & & 539.05 & $\begin{array}{l}\sigma^{*} \text { shape } \\
\text { resonance }\end{array}$ \\
\hline & 537.00 & $\mathrm{IP}, \mathrm{O}_{6}$ & & 537.45 & $\mathrm{IP}, \mathrm{O}_{2}, \mathrm{O}_{6}$ & & 536.85 & $\mathrm{IP}, \mathrm{O}_{2}, \mathrm{O}_{6}$ \\
\hline
\end{tabular}

${ }^{a}$ Ionization potentials are also given. T1 and T2 indicate tautomers 1 and 2 of hypoxanthine. The complete table with assignments of the observed NEXAFS features using the results of the present $\mathrm{ADC}(2)$ polarization propagator is given as Supporting Information.

three prominent bands $\mathrm{A}, \mathrm{C}$, and $\mathrm{D}$, as well as two weaker structures $\mathrm{B}$ and $\mathrm{E}$. The first peak at $399.52 \mathrm{eV}$ corresponds to peak $\mathrm{A}$ of guanine ${ }^{42}$ which was assigned to two resonances. These resonances are due to the energetically lowest transitions from $\mathrm{N}_{9}$ and $\mathrm{N}_{3}$ 1s levels to $\pi^{*}$ orbitals which give rise to the final many-electron valence states, $\mathrm{V}_{1}$. The assignment here corresponds to that case, that is, $\mathrm{A}$ is assigned to resonances of the imino nitrogen atoms, $\mathrm{N}_{3}$ in both tautomers, and $\mathrm{N}_{7}$ of tautomer 1 and $\mathrm{N}_{9}$ of tautomer 2. The weak peak B at 400.42 $\mathrm{eV}$, which was seen as a shoulder in the spectrum of guanine, is 
assigned mainly to transitions to $\mathrm{V}_{2}$, where each $\mathrm{V}_{2}$ is the second lowest valence state for the given core-hole configuration. ${ }^{42}$ Our calculations do not exclude some valence/3pRydberg mixing for this group of states. The next band $\mathrm{C}$ at $401.59 \mathrm{eV}$ is assigned mainly to amino group transitions to $\mathrm{V}_{1}$, i.e. from $\mathrm{N}_{1}$ in both tautomers, and $\mathrm{N}_{7}$ or $\mathrm{N}_{9}$. The band also comprises relatively strong $3 \mathrm{~s}$ Rydberg transitions (see Supporting Information). The weak broad peak D is due to $\mathrm{N}_{3} 1 \mathrm{~s} \rightarrow \mathrm{V}_{3} / 4 \mathrm{p}\left(\mathrm{V}_{2} / 4 \mathrm{p}\right)$ transitions of both tautomers, where again the final state could not be unambiguously assigned to either valence or $4 p$ Rydberg states. Several others transitions mainly of Rydberg character also contribute to this band. The peak E has mainly Rydberg character.

The oxygen 1s photoabsorption spectra of Xan, Hyp and Caff are displayed in Figure 4c. The strong, sharper peaks at lower photon energy are mainly due to transitions to $V_{1}$ states, while the broader features (higher photon energy) are the results of transitions to the other valence and Rydberg states below the ionization thresholds and to $\sigma^{*}$ states above the ionization threshold. In Figure $4 c$ hypoxanthine has one main feature due to the single oxygen atom in its structure, while xanthine and caffeine have double peaks, resulting from the excitation of two oxygen atoms. The O 1s NEXAFS spectra of xanthine and caffeine are very similar and can be subdivided into two distinct parts: the low-energy part consists of the two intense maxima A and B while the high energy part is mostly one broad resonance. The pyrimidine ring of these compounds is similar to that of thymine, ${ }^{40}$ and as in that case, the peaks A and $\mathrm{B}$ are due to the valence transitions $\mathrm{O}_{6} 1 \mathrm{~s} \rightarrow \mathrm{V}_{1}$ and $\mathrm{O}_{2} 1 \mathrm{~s}$ $\rightarrow \mathrm{V}_{1}$, respectively (Table 5). In Figure $4 \mathrm{c}$ the resonance $A$ (at $531.59 \mathrm{eV}$ for Xan and at $531.65 \mathrm{eV}$ for Caff) has lower intensity, while resonance B (at $532.29 \mathrm{eV}$ for Xan and 532.43 $\mathrm{eV}$ for Caff) has higher peak intensity. This trend is reproduced by the calculated oscillator strengths for the transitions under consideration, though it is not as pronounced as in the experimental spectra (see Supporting Information). Since the $\mathrm{O} 1 \mathrm{~s}$ binding energies of the two oxygen atoms are not resolved, but the $1 \mathrm{~s} \rightarrow \pi^{*}$ resonances are separated in energy, we conclude that the main effect is due to polarization (electronic structure rearrangement in response to the excited electron) and final state electron correlation, and not due to the ground state correlation or orbital relaxation.

\section{CONCLUSIONS}

X-ray absorption and photoemission spectroscopy have been used to study the electronic structure of xanthine, hypoxanthine, and caffeine in the gas phase. The experimental XPS and NEXAFS data have been compared with computational results, and with the spectra of the related compounds, guanine and adenine. The photoabsorption spectra are dominated by transitions from core levels to unoccupied $\pi$ states, but also show clear structures due to Rydberg transitions. The photoemission spectra presented here cover the $\mathrm{C} 1 \mathrm{~s}, \mathrm{~N} 1 \mathrm{~s}$, and $O$ 1s single hole state regions and the energetic shifts in these spectra due to the chemical differences of each xanthine derivative were evaluated and discussed. The calculations reproduce the XPS experimental spectral profiles of hypoxanthine only when the two most stable tautomers (oxo-N(9)$\mathrm{H}$ and oxo-N(7)-H) are accounted for in the theoretical modeling. Although the manifestation of tautomerism in the experimental spectra is less pronounced than in previous cases we have studied, the present theoretical results strongly support the presence of two tautomers in the gas phase under the experimental conditions in an approximate ratio of $1: 2$, which corresponds to the ground-state $\Delta G(298 \mathrm{~K})$ difference of 2.38 $\mathrm{kJ} / \mathrm{mol}$.

\section{ASSOCIATED CONTENT}

\section{Supporting Information}

Complete list of the calculated excitation energies and intensities for the vertical core-level transitions of Hyp, Xan, and Caff together with the assignment of the observed bands. This material is available free of charge via the Internet at http://pubs.acs.org.

\section{AUTHOR INFORMATION}

\section{Corresponding Author}

*Telephone: ++39 0403758287. Fax: ++390403758565. Email: Prince@Elettra.Trieste.It.

\section{Present Addresses}

${ }^{\ddagger}$ Aarhus University, Department of Physics and Astronomy, Ny Munkegade 120, 8000 Aarhus C, Denmark

\#Forschungszentrum Jülich $\mathrm{GmbH}$, Peter Grünberg Institute (PGI-6), 52425 Jülich, Germany

\section{Notes}

The authors declare no competing financial interest.

\section{ACKNOWLEDGMENTS}

O.P. acknowledges financial support from the CEI (Central European Initiative). We thank Christian Leghissa for excellent technical support, and our colleagues at Elettra for their assistance, and for providing high quality synchrotron light. The authors are grateful to E. V. Gromov for help in conducting the $\mathrm{ADC}(4)$ calculations. We are also thankful to Prof. J. Schirmer for useful suggestions and interest in this work.

\section{REFERENCES}

(1) Hughes, M. N. The Inorganic Chemistry of Biological Processes, 2nd ed.; John Wiley \& Sons: New York, 1981.

(2) Hurst, D. T. An Introduction to the Chemistry and Biochemistry of Pyrimidines, Purines and Pteridines: Wiley: New York, 1980.

(3) Stryer, L. Biochemistry; Freeman, W.H. and Company: New York, 1988.

(4) Miyakawa, S.; Cleaves, H .J.; Miller, S .L. Origins Life Evolution Biosphere 2002, 32, 209-218.

(5) Stoks, P. G.; Schwartz, A. W. Geochim. Cosmochim. Acta 1982, 46, 309-315.

(6) Biaggioni, I.; Paul, S.; Puckett, A.; Arzubiaga, C. J. Pharmacol. Exp. Ther. 1991, 258, 588-593.

(7) de Vries, M. S.; Hobza, P. Annu. Rev. Phys. Chem. 2007, 58, 585612.

(8) Trofimov, A. B.; Schirmer, J.; Kobychev, V .B.; Potts, A. W.; Holland, D. M. P.; Karlsson, L. J. Phys. B: At. Mol. Opt. Phys. 2006, 39, 305-329.

(9) Jochims, H.-W.; Schwell, M.; Baumgartel, H.; Leach, S. Chem. Phys. 2005, 314, 263-282.

(10) Schwell, M.; Jochims, H.-W.; Baumgärtel, H.; Dulieu, F.; Leach, S. Planet. Space Sci. 2006, 54, 1073-1085.

(11) Šponer, J.; Leszczynski, J.; Hobza, P. Biopolymers 2001, 61, 331.

(12) Hush, N. S.; Cheung, A. S. Chem. Phys. Lett. 1975, 34, 11-13.

(13) Dougherty, D.; Younathan, E .S.; Voll, R.; Abdulnur, S.; McGlynn, S. P. J. Electron Spectrosc. Relat. Phenom. 1978, 13, 379-393.

(14) Ajò, D.; Fragala, I.; Granozzi, G.; Tondello, E. Spectrochim. Acta 1978, 34A, 1235-1238.

(15) Lin, J.; Yu, C.; Peng, S.; Akiyama, I.; Li, K.; Lee, L .K.; LeBreton, P. R. J. Phys. Chem. 1980, 84, 1006-1012. 
(16) Peeling, J.; Hruska, F .E.; McIntyre, N. S. Can. J. Chem. 1978, $56,1555-1561$.

(17) Edwards, H. G. M.; Munshi, T.; Anstis, M. Spectrochim. Acta 2005, 61A, 1453-1459.

(18) Gunasekaran, S.; Sankari, G.; Ponnusamy, S. Spectrochim. Acta 2005, 61A, 117-127.

(19) Fernández-Quejo, M.; de la Fuente, M.; Navarro, R. J. Mol. Struct. 2005, 744, 749-757.

(20) Ucun, F.; Sağlam, A.; Güçlü, V. Spectrochim. Acta 2007, 67A, 342-349.

(21) Ramaekers, R.; Dkhissi, A.; Adamowicz, L.; Maes, G. J. Phys. Chem. A. 2002, 106, 4502-4512.

(22) Kondratyuk, I. V.; Samijlenko, S. P.; Kolomiets, I. M.; Hovorun,

D. M. J. Mol. Struct. 2000, 523, 109-118.

(23) Hernández, B.; Luque, F. J.; Orozco, M. J. Org. Chem. 1996, 61, 5964-5971.

(24) Shukla, M. K.; Leszczynski, J. J. Phys. Chem. A 2000, 104, 30213027.

(25) Civcir, P. U. J. Mol. Struct. (THEOCHEM) 2001, 545, 7-15.

(26) Costas, M. E.; Acevedo-Chávez, R. J. Phys. Chem. A 1997, 101, 8309-8318.

(27) Gerega, A.; Lapinski, L.; Nowak, M. J.; Rostkowska, H. J. Phys. Chem. A 2006, 110, 10236-10244.

(28) Shukla, M. K.; Leszczynski, J. J. Phys. Chem. A 2003, 107, 55385543.

(29) Kesimli, B.; Topacli, A.; Topacli, C. J. Mol. Struct. 2003, 645, 199-204.

(30) de Matas, M.; Edwards, H. G. M.; Lawson, E. E.; Shields, L.; York, P. J. Mol. Struct. 1998, 440, 97-104.

(31) Derollez, P.; Correia, N. T.; Danede, F.; Capet, F.; Affouard, F.; Lefebvre, J.; Descamps, M. Acta Crystallogr. B 2005, 61, 329-334.

(32) Callahan, M. P.; Crews, B.; Abo-Riziq, A.; Grace, L.; de Vries, M. S.; Gengeliczki, Z.; Holmes, T. M.; Hill, G. A. Phys. Chem. Chem. Phys. 2007, 9, 4587-4591.

(33) Kim, D.; Kim, H. M.; Yang, K. Y.; Kim, S. K.; Kim, N. J. J. Chem. Phys. 2008, 128, 134310.

(34) Bondesson, L.; Mikkelsen, K. V.; Luo, Y.; Garberg, P.; Ågren, H. Spectrochim. Acta 2007, 66A, 213-224.

(35) Edwards, H. G. M.; Farwell, D. W.; de Oliveira, L. F. C.; Alia, J.M.; le Hyaric, M.; de Ameida, M. V. Anal. Chim. Acta 2005, 532, 177186

(36) Egawa, T.; Kamiya, A.; Takeuchi, H.; Konaka, S. J. Mol. Struct. 2006, 825, 151-157.

(37) Farrokhpour, H.; Fathi, F. J. Comput. Chem. 2011, 32, 24792491.

(38) Feyer, V.; Plekan, O.; Richter, R.; Coreno, M.; Prince, K. C. Chem. Phys. 2009, 358, 33-38.

(39) Prince, K. C.; Blyth, R. R.; Delaunay, R.; Zitnik, M.; Krempasky, J.; Slezak, J.; Camilloni, R.; Avaldi, L.; Coreno, M.; Stefani, G.; et al. Sync. Radiat. 1998, 5, 565-568.

(40) Plekan, O.; Feyer, V.; Richter, R.; Coreno, M.; de Simone, M.; Prince, K. C.; Trofimov, A. B.; Gromov, E. V.; Zaytseva, I. L.; Schirmer, J. Chem. Phys. 2008, 347, 360-375.

(41) Feyer, V.; Plekan, O.; Richter, R.; Coreno, M.; Prince, K. C.; Carravetta, V. J. Phys. Chem. A 2008, 112, 7806-7815.

(42) Plekan, O.; Feyer, V.; Richter, R.; Coreno, M.; Vall-llosera, G.; Prince, K. C.; Trofimov, A. B.; Zaytseva, I. L.; Moskovskaya, T. E.; Gromov, E. V.; et al. J. Phys. Chem. A. 2009, 113, 9376-9385.

(43) Feyer, V.; Plekan, O.; Richter, R.; Coreno, M.; Vall-llosera, G.; Prince, K. C.; Trofimov, A. B.; Zaytseva, I. L.; Moskovskaya, T. E.; Gromov, E. V.; et al. J. Phys. Chem. A 2009, 113, 5736-5742.

(44) Feyer, V.; Plekan, O.; Richter, R.; Coreno, M.; de Simone, M.; Prince, K. C.; Trofimov, A. B.; Zaytseva, I. L.; Schirmer, J. J. Phys. Chem. A. 2010, 114, 10270-10276.

(45) Schirmer, J. Phys. Rev. A 1982, 26, 2395-2416.

(46) Trofimov, A. B.; Schirmer, J. J. Phys. B: At. Mol. Phys. 1995, 28, 2299-2324.

(47) Cederbaum, L. S.; Domcke, W.; Schirmer, J. Phys. Rev. A 1980, 22, 206-222.
(48) Barth, A.; Schirmer, J. J. Phys. B: At. Mol. Phys. 1985, 18, 867885

(49) Schirmer, J.; Barth, A.; Tarantelli, F. Chem. Phys. 1988, 122, 915.

(50) Hehre, W. J.; Ditchfield, R.; Pople, J. A. J. Chem. Phys. 1972, 56, 2257-2261

(51) Clark, T.; Chandrasekhar, J.; Spitznagel, G. W.; von Ragué Schleyer, P. J. Comput. Chem. 1983, 4, 294-301.

(52) Schirmer, J.; Cederbaum, L. S.; Walter, O. Phys. Rev. A 1983, 28, $1237-1259$.

(53) von Niessen, W.; Schirmer, J.; Cederbaum, L. S. Comp. Phys. Rep. 1984, 1, 57-125.

(54) Schirmer, J.; Angonoa, G. J. Chem. Phys. 1989, 91, 1754-1761.

(55) Angonoa, G.; Walter, O.; Schirmer, J. J. Chem. Phys. 1987, 87, 6789-6801.

(56) Dunning, T. H., Jr. J. Chem. Phys. 1989, 90, 1007-1023.

(57) Kendall, R. A.; Dunning, T. H., Jr.; Harrison, R. J. J. Chem. Phys. 1992, 96, 6796-6806.

(58) Woon, D. E.; Dunning, T. H., Jr. J. Chem. Phys. 1994, 100, 2975-2988.

(59) The $\mathrm{ADC}(3)$ and constant diagram codes were originally written by G. Angonoa, O. Walter, J. Schirmer; further developed by M. K. Scheller and A. B. Trofimov. The one-particle Green's function ADC(4)/CVS code was written by G. Angonoa, O. Walter, and J. Schirmer; direct treatment of the first-order matrix elements and diagonalization was due to F. Tarantelli. Polarization propagator ADC code was written by A. B. Trofimov, G. Stelter, and J. Schirmer.

(60) Schmidt, M. W.; Baldridge, K. K.; Boatz, J. A.; Elbert, S. T.; Gordon, M. S.; Jensen, J. H.; Koseki, S.; Matsunaga, N.; Nguyen, K. A.; Su, S. J.; et al. J. Comput. Chem. 1993, 14, 1347-1363. Gordon, M. S.; Schmidt, M. W. In Theory and applications of computational chemistry, the first forty years; Dykstra, C. E., Frenking, G., Kim, K. S., Scuseria, G. E. Eds.; Elsevier: Amsterdam, 2005; Chapter 41, p 1167.

(61) Gaussian 98, Revision A.7, Frisch, M. J. ; Trucks, G. W. ; Schlegel, H. B.; Scuseria, G. E. ; Robb, M. A.; Cheeseman, J. R. ; Zakrzewski, V. G.; Montgomery, Jr., J. A.;. Stratmann, R. E.; Burant, J. C.; et al., Gaussian, Inc.: Pittsburgh, PA, 1998.

(62) Becke, A. D. J. Chem. Phys. 1993, 98, 5648-1377.

(63) Lee, C.; Yang, W.; Parr, R. G. Phys. Rev. B 1988, 37, 785-789.

(64) Krishnan, R.; Binkley, J. S.; Seeger, R.; Pople, J. A. Chem. Phys. 1980, 72, 650-654.

(65) Cederbaum, L. S.; Domke, W. Adv. Chem. Phys. 1977, 36, 205344.

(66) Cederbaum, L. S.; Domcke, W.; Schirmer, J.; von Niessen, W. Adv. Chem. Phys. 1986, 65, 115-159.

(67) Schirmer, J.; Braunstein, M.; Lee, M.-T.; McKoy, V. In VUV and soft $X-$ ray photoionization; Becker, U., Shirley, D. A., Eds.; Plenum: New York, 1996; pp 105-133.

(68) Bolognesi, P.; Mattioli, G.; O’Keeffe, P.; Feyer, V.; Plekan, O.; Ovcharenko, E.; Prince, K. C.; Coreno, M.; Amore Bonapasta, A.; Avaldi, L. J. Phys. Chem. A 2009, 113, 13593-13600. 